\title{
Kernos
}

Revue internationale et pluridisciplinaire de religion

grecque antique

32 | 2019

Varia

\section{L'olivier, identité et rempart d'Athènes : un épisème de la cité ?}

\section{Sonia Darthou}

\section{(2) OpenEdition \\ Journals}

\section{Édition électronique}

URL : https://journals.openedition.org/kernos/3115

DOI : 10.4000/kernos.3115

ISSN : 2034-7871

\section{Éditeur}

Centre international d'étude de la religion grecque antique

\section{Édition imprimée}

Date de publication : 1 décembre 2019

Pagination : 49-79

ISBN : 978-2-87562-229-7

ISSN : 0776-3824

\section{Référence électronique}

Sonia Darthou, «L'olivier, identité et rempart d'Athènes : un épisème de la cité ? », Kernos [En ligne], 32 | 2019, mis en ligne le 01 octobre 2021, consulté le 02 août 2022. URL : http://journals.openedition.org/ kernos/3115; DOI : https://doi.org/10.4000/kernos.3115

Ce document a été généré automatiquement le 2 août 2022

Tous droits réservés 


\title{
L'olivier, identité et rempart d'Athènes : un épisème de la cité ?
}

\author{
Sonia Darthou
}

Il est un plant dont je ne sache pas qu'un pareil ait surgi jamais [...] un plant indomptable, qui se refait seul, un plant qui est l'effroi des armes ennemies [...],

l'olivier au feuillage glauque, le nourricier de nos enfants, l'arbre que personne ni jeune ni vieux ne peut détruire ou saccager. Le regard vigilant de Zeus Morios

ne le quitte pas, et pas davantage celui d'Athéna

Glaukôpis.

SOPHOCLE, EEdipeàColone, 691-705.

1 Au sein du mythe de fondation qui enracine les Athéniens sur leur territoire et affiche l'identité de la cité, l'olivier occupe une place centrale. Cet arbre mythique est le signe de la puissance d'Athéna, un témoignage de sa présence protectrice et un symbole du destin de la polis. Comme une épiphanie polysémique de la déesse Poliade, il affiche des qualités très politiques : la fertilité, la civilisation, l'ancrage, la force indomptable, la résistance et la renaissance. Mais l'olivier, qualifié par Sophocle « d'effroi des armes ennemies ", se retrouve aussi sur les vases en céramique d'Athènes où il apparaît de manière inédite en épisème de bouclier. Après avoir dessiné la symbolique plurielle de l'olivier, on se concentrera sur une approche iconographique qui fait apparaître que l'arbre d'Athéna oscille entre référence identitaire et rempart fascinant face aux ennemis.

\section{Prologue à un olivier épisématique}

\section{L'olivier, signe de l'eris fondatrice d'Athènes}

Dans le célèbre mythe de fondation d'Athènes, les deux protagonistes divins Athéna et Poséidon, qui se disputent le patronage de la cité, produisent des signes qui doivent les 
départager. Poséidon fait surgir une mer en frappant de son trident le sol de l'Acropole, tandis qu'Athéna fait croître un olivier sur la colline pierreuse d'Athènes ${ }^{1}$. La victoire de la déesse qui remporte le titre de Poliade est acquise grâce à ce premier olivier ${ }^{2}$, un arbre à fruits qui pousse sur le rocher sacré, car nos sources insistent sur cette notion de croissance et de fertilité3. Le terme dédié à l'olivier d'Athéna est elaia ${ }^{4}$, l'olivier domestique et cultivé et non kotinos, l'olivier «sauvage» appelé l'oléastre. Cette différentiation, loin d'être une anecdote botanique, est cardinale car Athéna est justement associée étroitement à cet olivier "domestiqué » qui requiert la technique des hommes afin de donner de belles olives à maturité, charnues et savoureuses ${ }^{5}$. L'olivier symbolise également la vitalité de la nature : il ne perd pas ses feuilles, son feuillage est éternellement vert ${ }^{6}$, il a une longévité exceptionnelle ${ }^{7}$, il est imputrescible ${ }^{8}$ et il a la capacité de renaître de lui-même ${ }^{9}$. C'est en vertu de ce principe vital prodigieux que l'on peut relire le célèbre témoignage de Pausanias ${ }^{10}$ à propos de la « renaissance » nocturne de l'olivier de l'Acropole au moment de l'invasion barbare lors des guerres médiques : une repousse fulgurante qui devient le symbole de la vitalité de la polis, puisque l'olivier était le symbole initial de sa fondation. Déesse technicienne associée à la $m \bar{e} t i s^{11}$, plus ouvrière ${ }^{12}$ que fruitière ${ }^{13}$, Athéna fait donc surgir un olivier paidotrophos qui apparaît comme un symbole nourricier, un signe de civilisation, de terre cultivée ${ }^{14}$ et de résistance qui incarne un "début» politique pour la cité qui portera désormais le nom d'Athènes ${ }^{15}$.

3 Mais l'olivier apparaît également comme un arbre articulé à la sédentarisation, à l'ancrage et à l'identité citoyenne autochtone.

\section{Sédentarisation, ancrage, identité}

Dans le serment des éphèbes athéniens, les futurs citoyens s'engageaient à l'issue de leur formation armée en prenant notamment à témoins Thallô et Auxô (déesses des bourgeonnements et de la croissance), associées aux «bornes de la patrie, les blés, les orges, les vignes, les oliviers, les figuiers $»^{16}$. Dans ce serment qui crée un lien identitaire entre toute une classe d'âge ${ }^{17}$, les éphèbes jurent collectivement de défendre la patrie tout en réactualisant leurs liens avec la terre fructifère, céréalière et vinicole. Mais Plutarque indique que les oliviers ne doivent pas se réduire à des arbres fruitiers ${ }^{18}$ : ils doivent être considérés comme des "bornes» du territoire athénien. L'olivier au chevelu racinaire déployée ${ }^{19}$ n'est pas seulement un producteur d'olives nourricières, il semble contribuer, comme les constructions de pierre, à architecturer le territoire, c'est-à-dire à ancrer légitimement la cité et sa communauté citoyenne sur sa terre. L'olivier d'Athéna, devenu l'olivier d'Athènes, véritable racine mythique de la cité, se révèle en effet être un axe et un signe de la polis. À la fois un et multiple, inscrit dans la maison et dans la cité, l'olivier apparaît en tension entre identité individuelle et identité collective. Effectivement, l'olivier initial comme signe de l'eris se fait multiple à travers ses "héritiers", les moriai ${ }^{20}$, ces oliviers sacrés gérés par la cité et dont le déracinement pouvait, à l'époque archaïque, entraîner la peine capitale édictée par l'Aréopage ${ }^{21}$. Arbre politique, astè elaia ${ }^{22}$, il apparaît également sur les monnaies, ces célèbres tétradrachmes qui représentent le "prototype du monnayage civique grec d'époque classique $»^{23}$. Mais l'olivier est aussi le signe de la naissance d'un enfant mâle car, selon Hésychius ${ }^{24}$, on suspendait à cette occasion un rameau de l'arbre d'Athéna à la porte de la maison. Sur la porte qui articule espace domestique et espace civique, l'olivier devient la marque visible d'un futur citoyen car chaque nouvelle naissance 
masculine est comme un "prolongement» du corps civique. Ce signe de naissance individuelle masculine qui hérite de la symbolique de l'olivier d'Athéna et se retrouve dans le serment des éphèbes puis, on le verra, sur les boucliers, apparait donc comme un signe d'identité citoyenne athénienne. D'ailleurs, c'est une couronne d'olivier que Créuse choisit de placer dans la corbeille d'Ion à sa naissance : un objet «identitaire » qui doit le protéger après avoir été exposé et qui va permettre sa reconnaissance et sa réintégration dans la lignée autochtone ${ }^{25}$.

5 L'olivier apparaît effectivement sur les représentations de la naissance d'Éritchthonios au sein des vases attiques ${ }^{26}$. Sur un cratère en calice à figures rouges du Peintre de Talos $\left(\right.$ Fig. 1 ${ }^{27}$, Gaia tend le nouveau-né, couronné d'olivier par une Nikè en vol, à Athéna, tandis qu'un olivier enracine la scène à Athènes derrière la déesse Terre et que des rameaux émergent du sol, comme un écho au surgissement « végétal » d'Érichthonios, le premier citoyen athénien. Sur un cratère en calice à figures rouges attribué au Peintre de Nicias (Fig. 2) ${ }^{28}$, on voit Gaia tendant Érichthonios à la déesse Athéna, dont le pied semble posé sur un "tronc » d'où émerge un rameau d'olivier portant des olives, la déesse étant elle-même surplombée par une chouette tenant une couronne d'olivier aux fruits clairement rehaussés de blanc. La scène est d'ailleurs saturée d'olivier ${ }^{29}$, comme de multiples rappels à l'ancrage athénien de la scène. Mais un autre vase semble mettre en écho ce premier autochtone et Ion. Sur une péliké à figures rouges (Fig. 3) ${ }^{30}$, Érichthonios émerge d'une "corbeille " posée sur un "décor rocheux » entouré par deux serpents, en faisant un " geste de salut » à la déesse Athéna qui se tient devant lui. Sur ces rochers, une "ciste» aux croisillons évoquant la vannerie est cerclée d'une couronne d'olivier qui porte des fruits, ce qui inscrit Érichthonios dans l'espace symbolique athénien ; cela rappelle la couronne que Créuse a placée dans la corbeille de naissance d'Ion, objet ultime qui permet sa légitimation comme athénien et autochtone.

Or, la naissance d'Érichthonios ne met pas en scène la naissance d'un enfant, elle construit une identité collective à travers un réseau de filiation avec Athéna, Zeus et Gaia, et légitime l'ancrage sur le territoire. Le mythe d'Érichthonios constitue en effet un processus de fondation qui permet de s'approprier le territoire par la naissance et de transmettre une identité à tous les descendants de cet autochtone primordial ${ }^{31}$. En terre d'Athènes, on a pu démontrer qu'il n'y a pas un fondateur, mais des autochtones qui, par leurs singulières naissances, multiplient la figure inaugurale du fondateur, symbolisent les racines de la cité et garantissent ainsi l'autofondation de la polis ${ }^{32}$. Les Athéniens, qui se revendiquent "tous frères nés d'une même mère " dans ce mythe fondateur aux métaphores très végétales ${ }^{33}$, et qui sont issus d'une "racine (rizē) commune $\aleph^{34}$, semblent comme des rameaux émergeant d'un tronc commun qui partagent la même identité autochtone héritée à la naissance. L'olivier qui se renouvelle en permanence ${ }^{35}$, associé dans les représentations à cette première naissance citoyenne mythique qui sera prolongée et réactualisée en permanence par les naissances masculines dans la cité, apparaît bien comme un arbre étroitement associé à l'identité athénienne. Du rocher à la porte, d'Érichthonios aux nouveau-nés mâles, l'olivier tisse des liens entre ancêtre mythique et futurs citoyens.

7 Mais l'olivier ne se réduit pas à un signe identitaire. Apposé en épisème sur le bouclier, il se fait brillant, redouble l'éclat du guerrier et propose un motif fascinant qui concourt à effrayer l'adversaire. 


\section{L'olivier : un épisème de la cité ?}

\section{L'olivier sur les boucliers}

8 La métaphore sophocléenne de l'olivier comme objet d'effroi (phobèma) qui «verse la peur » sur les ennemis (daiōn) ${ }^{36}$ complétée par la scholie (tois polemiois) ${ }^{37}$, nous a incitée à chercher du côté des motifs épisématiques. Or, ces vers trouvent effectivement un écho dans plusieurs épisèmes de boucliers qui apparaissent sur les vases attiques. Le bouclier est l'élément central de la panoplie hoplitique, c'est le rempart défensif du guerrier, mais également une arme offensive qui éblouit et résonne dans le combat ${ }^{38}$. Mais l'hoplon est aussi comme la métaphore du combattant, son arme identitaire ${ }^{39}$, et les images qu'il porte en épisème, destinées à l'ennemi frontal, redoublent le corps du guerrier tout en proposant une "image" symbolique qui fonctionne comme un "signe" $(s \bar{e} m a)^{40}$. À l'intérieur d'une pluralité de motifs dont la liste complexe et plurielle ne saurait être exhaustive - gorgoneion, figures léonine ou taurine, griffon, tête chevaline, serpent, dauphin, trépied, centaure ${ }^{41}-$ qui renvoient à une iconographie «identitaire », apotropaïque ou qui opèrent des jeux/décalages visuels ${ }^{42}$, on trouve plusieurs exemples d'épisèmes d'olivier sur le bouclier de la déesse Poliade d'Athènes.

On pourra opposer que l'identification des couronnes de feuillage ou des rameaux peut paraître incertaine puisque, si les représentations doivent permettre la reconnaissance du motif, elles n'ont pas de vocation réaliste au sens photographique ; on peut parfois hésiter, en regardant simplement la taille ou la forme des feuilles, quand il n'y a pas la présence de baies couronnées ou de fruits, entre laurier, myrte ou olivier, si l'on s'inscrit dans une perspective purement «botanique $»^{43}$. Pourtant, il ne saurait y avoir de réalisme botanique dans les représentations céramiques car les éléments végétaux sont à appréhender avec les figures qui les entourent, les manipulent, les portent ou les détiennent; ils ne sont pas indépendants mais en interaction avec les acteurs de la scène et ont un rôle à la fois dans la caractérisation et la manifestation des figures et de leurs actions ${ }^{44}$. Effectivement, c'est plutôt le contexte, la présence d'Athéna, le sens et l'enjeu de la scène qui influencent la lecture ${ }^{45}$ tout comme la présence de l'olivier en épisème contribue à construire la cohérence de l'image. Si l'épisème, en tant qu'image, apparaît bien, selon les mots de F. Lissarrague, comme "porteur de valeurs symboliques et vecteur d'identité ", il ne s'inscrit pas seulement en cohérence avec son porteur, mais également avec son environnement et les autres acteurs de la scène dans un effet « réflexif $~^{46}$ au caractère « référentiel »; comme une « citation visuelle ${ }^{47}$ qui s'appuie sur un imaginaire partagé.

L'olivier, comme "arbre-attribut » de la déesse, comme «signe de l'eris », trouve parfaitement sa place sur son bouclier; mais l'olivier, sur l'espace de l'hoplon, peut également revêtir la dimension plus apotropaïque de l'épisème et se rapprocher du motif qui orne usuellement l'arme d'Athéna : le gorgoneion.

\section{L'olivier comme épisème du bouclier d'Athéna}

11 Sur cinq amphores panathénaïques (Fig.4-8) ${ }^{48}$, la déesse Athéna, représentée de manière canonique sur le type de la Promachos, est munie de sa panoplie guerrière, casquée, cuirassée, sa lance pointée comme pour pourfendre un ennemi imaginaire. 
Elle brandit face au spectateur du vase un large bouclier rond qui renforce son attitude offensive et dont l'épisème est constitué d'une couronne végétale qui, au vu du contexte, se lit comme une couronne d'olivier. Cet épisème très réflexif, qui « signe » et redouble la figure d'Athéna, intensifie les liens entre la déesse et l'arbre citoyen tout en captant l'attention. Car cette couronne qui déploie ses feuilles met également en lumière la rotondité de l'espace central de la bossette et redouble, en un cercle concentrique, la circularité du bouclier déjà soulignée par les incisions de l'orle ${ }^{49}$, ce qui contribue à renforcer un effet visuel "hypnotique» pour le spectateur et, symboliquement, pour celui qui se tient face au bouclier : l'ennemi.

Mais on retrouve, hors de ce contexte panathénaïque où ce feuillage peut rappeler la couronne de victoire athlétique ${ }^{50}$, l'olivier en épisème du bouclier d'Athéna ${ }^{51}$ sur des vases attiques à figures rouges ${ }^{52}$. Sur un lécythe conservé à Hanovre (Fig. 9) ${ }^{53}$, Athéna, qui a déposé à terre son bouclier, fait face à Nikè présentant une couronne. La couronne végétale en épisème qui évoque l'olivier ${ }^{54}$ fait écho ici à la couronne de Nikè, et incite à relier l'olivier au thème de la victoire ${ }^{55}$. Une inscription exclamatoire $e^{56}$ comme sortie de la bouche d'Athéna semble s'inscrire en résonnance de cet épisème : Alkimachos kalos "Celui qui combat avec courage est beau ». Athéna et Nikè, graphiquement reliées par l'inscription, semblent mises en triangulation avec le bouclier à l'épisème d'olivier pour créer une composition autour de la force guerrière et de la victoire. Sur un cratère à volutes à figures rouges (Fig. 10) ${ }^{57}$, Athéna, assise et tenant des rameaux d'olivier qu'elle semble " agiter » devant elle, fait face à un guerrier couronné à la cuirasse écaillée et étoilée. Sur son bouclier posé derrière elle trône, en épisème, une couronne d'olivier qui fait écho à ses rameaux. Enfin, sur un autre lécythe (Fig.11) ${ }^{58}$, Athéna est représentée tenant la salpinx, et son bouclier posé à terre porte cette fois un épisème formé d'une chouette aux yeux grands ouverts posée sur un rameau d'olivier. Cette chouette dont le regard "glauque » rappelle la couleur "glauque » de l'olivier et le regard de la déesse Glaukôpis contribue à créer, comme épisème, un système de signes aussi redondants que " fascinants ${ }^{59}$ qui concourt à éblouir l'adversaire.

13 L'olivier, s'il rappelle l'arbre identitaire d'Athéna ${ }^{60}$ et la couronne de victoire des jeux panathénaïques, prend en épisème une résonnance plus guerrière: apposé sur le bouclier, il s'affiche comme une image qui intensifie sa puissance de Promachos. Il rappelle cette sémantique de phobos (peur-épouvante) évoquée par Sophocle car l'épisème présente de manière offensive la face visible et symbolique de son porteur protégé par cet écran de bronze. D'ailleurs, un cratère en calice du Peintre de Kékrops ${ }^{61}$ nous invite à mettre en écho l'olivier et le gorgoneion. Dans cette scène complexe qui évoque la naissance d'Érichthonios, Athéna et Kékrops se font face autour d'un coffret qui rappelle la ciste du premier citoyen autochtone, entourés de spectateurs divins qui s'étagent dans le champ. Cette ciste, recouverte d'un tissu dont le motif fait écho au vêtement de la déesse, constitue le point focal de la scène et est totalement insérée dans un décor d'oliviers portant des fruits : elle est traversée par un olivier, tandis que des rameaux semblent émerger à ses côtés. Sans entrer dans l'analyse de la composition $^{62}$, on se focalisera sur la figure d'Athéna et surtout sur son bouclier. Sur une face (Fig. 12 et 12bis pour le détail), la déesse, debout, une phiale à la main, ne garde de sa panoplie guerrière que sa lance, son casque et son bouclier figurant aux mains d'une figure féminine couronnée d'olivier assise derrière elle. Diverses analyses se contredisent autour de ces deux figures étroitement associées par les armes d'Athéna. Au lieu d'y voir une Athéna dédoublée ou de se prêter au jeu des identifications, on 
préfèrera identifier cette "femme" assise comme une figure "porte-armure ", qui garde à « disposition » les armes de la déesse. Ce qui nous intéresse, c'est la frontalité du casque qui semble "présenté " au regard et l'épisème du bouclier. Le casque, entouré d'un triple cimier qui accentue cette « face " guerrière ${ }^{63}$, rappelle les guerriers aux cheveux longs déployés qualifiés de gorgoterous (plus "gorgoniens ») ${ }^{64} \mathrm{ou}$ phoberoterous (plus terrifiants) ${ }^{65}$, et se rapproche d'un prosopon $^{66}$, les ouvertures oculaires braquées vers le spectateur. Ce casque semble être redoublé par l'épisème du bouclier d'Athéna qui affiche un gorgoneion ${ }^{67}$ frontal entouré d'une couronne d'olivier qui fait lui-même écho au gorgoneion placé sur l'égide de la déesse. La couronne d'olivier ${ }^{68}$, que nous avons rencontrée seule en épisème de bouclier, prend ici une résonnance particulière autour de la tête de la Gorgone; si elle focalise le regard et contribue à construire cette face d'épouvante, elle s'associe aussi étroitement à la signification du gorgoneion. D'autant plus que, sur l'autre face (Fig. 13), derrière Athéna, assise, casquée et munie de sa lance, une Nikè est accoudée sur le bouclier de la déesse qui porte à nouveau, en épisème, une couronne d'olivier (entourant peut-être un gorgoneion difficilement identifiable). Sur ce vase du Peintre de Kékrops, l'olivier semble redoubler la chevelure reptilienne de la Gorgone, associée étroitement au "phobos " ${ }^{69}$, et parachève sa face de terreur mortifère par une « chevelure de feuilles glauques ».

«Identitaire » et " apotropaïque » quand il est en épisème, l'olivier a-t-il également cette fonction « protectrice » quand il est apposé sur la porte de la maison où vient de naître un enfant mâle ${ }^{70}$, en plus d'être le signe de la naissance d'un futur athénien à l'«intérieur ", derrière la porte? Les indications très lacunaires des sources littéraires $^{71}$, comme les représentations de portes sur la céramique attique ${ }^{72}$, ne semblent pas permettre d'explorer plus avant ce dossier. En revanche, nous avons déjà évoqué combien l'olivier est un signe identitaire de naissance autochtone athénienne qui permet la reconnaissance, et la légitimation ${ }^{73}$. La présence de Kékrops, premier roi anguipède ayant institué le mariage ${ }^{74}$ qui donne un cadre légitime à la naissance et à la reconnaissance citoyenne, ne peut qu'appuyer cette lecture d'un olivier «signe » de citoyenneté légitime.

Signe d'Athéna, signe de la cité, signe d'un athénien, l'olivier partage avec le bouclier le champ sémantique du "sèmeion ${ }^{75}$ et semble incarner l'identité d'Athènes ${ }^{76}$ comme celle de ses citoyens. D'ailleurs, un vase nous porte au-delà de l'univers d'Athéna. Sur une amphore à figures rouges ${ }^{77}$ (Fig. 14) figurant une scène de départ de guerrier, un hoplite muni de sa lance tient son bouclier face au spectateur: en épisème, une couronne d'olivier dont les fruits sont clairement dessinés entoure une étoile centrale dont la couleur blanche, lumineuse, accentue la «brillance » du feuillage glauque et de la surface en bronze ${ }^{78}$. Un cratère en cloche à la manière du peintre des Niobides (Fig. 15) ${ }^{79}$ bordé d'une frise végétale ${ }^{80}$ peut être mis en parallèle : il présente un départ de guerrier qui, assis, casqué et la lance à la main, tend une phiale vers une femme couronnée qui approche une œnochoé pour effectuer une libation. Ce couple central est entouré d'une figure féminine tendant une bandelette de victoire et d'une figure masculine âgée tenant un sceptre et un rameau de feuillage (olivier ?). Or, le bouclier du guerrier maintenu à terre par la femme à l'œnochoé porte en épisème une couronne végétale qui peut être lue comme de l'olivier ${ }^{81}$. Sur l'amphore de New York en tout cas, où l'olivier est clairement identifiable, il s'agit d'une figure anonyme, qui incite à voir cet épisème d'olivier comme un motif de " combattant athénien ", à la fois identitaire et apotropaïque, rappelant la force du guerrier autochtone, enfant d'Athéna, associé à l'arbre indomptable depuis sa naissance. Car si l'olivier est un rempart, si l'olivier 
incarne vitalité, régénérescence, éternité, ancrage, il est aussi associé à la brillance, au miroitement, à l'éclat éblouissant; comme le bouclier hoplitique; comme le corps éclatant du guerrier ${ }^{82}$; comme le corps éclatant des dieux ${ }^{83}$.

L'olivier, seul végétal à porter une glauque frondaison ${ }^{84}$, s'insère en effet parfaitement dans l'univers de l'Athéna Glaukōpis, la déesse à l'« œil de bronze » ${ }^{85}$ accompagnée de la chouette au regard intense et frontal sur les représentations ${ }^{86}$, telle une sentinelle à la couleur singulière et brillante ${ }^{87}$ que l'on a déjà rencontrée posée sur un rameau en épisème ${ }^{88}$. L'olivier glauque à l'éclat "argenté", notamment quand il retourne sa frondaison au moment du soleil d'été avec une mètis toute athénienne ${ }^{89}$, affiche une feuille étincelante, d'une blancheur lumineuse, et miroite au soleil comme un bouclier de bronze ${ }^{90}$. Il est d'ailleurs décrit, dans les Troyennes d'Euripide, comme la "céleste couronne et parure d'Athènes la brillante ${ }^{91} »$. Dans Les Acharniens, Aristophane indique aussi que le bouclier, huilé, acquiert une brillance qui le fait miroiter : il en devient divinatoire et produit une "image oraculaire $»^{92}$. Mais une scholie à ces vers indique également que cet usage de huiler les boucliers a pour but d'effrayer l'ennemi ${ }^{93}$. Le bouclier de bronze brandi face aux ennemis telle une arme offensive, qui fait écho au regard pétrifiant de la Gorgone, rappelle ainsi la face «glauque » des feuilles d'olivier qui peuvent également contribuer, en épisème, à construire une figure guerrière « miroitante » et « éblouissante » face aux adversaires ou aux envahisseurs.

\section{Un olivier gorgonéen?}

17 La scène centrale d'une hydrie à figures rouges (Fig. 16) ${ }^{94}$ nous invite à aller plus loin pour prolonger cet aspect "gorgonéen » de l'olivier. Athéna casquée et munie de sa lance est représentée étendant sa main sur la Gorgone endormie d'où "émerge " un olivier, alors que Persée s'apprête à la décapiter, sa besace à la main. Athéna, l'olivier et la Gorgone s'entrelacent étroitement dans la composition puisque la main de la déesse croise le tronc d'olivier qui, lui-même, semble « pousser » de la Gorgone, déployant ses branches feuillues au-dessus d'elle et face au spectateur ${ }^{95}$. L'olivier ne saurait se réduire à un "marqueur» de paysage ou à un motif «décoratif » axial dans l'image ${ }^{96}$; la Gorgone n'apparaît pas non plus comme simplement allongée derrière un olivier ${ }^{97}$ "planté » sur une « ligne de sol $»^{98}$. N. Dietrich indique bien que les arbres auxquels les figures sont attachées doivent s'appréhender non comme des entités indépendantes du paysage, mais comme faisant partie intégrante de la figure représentée ${ }^{99}$. Ainsi, sur l'hydrie, même si cet exemple est assez unique, l'olivier semble graphiquement inséré dans le corps de la Gorgone : placé entre le buste et le bras replié, il parait émerger du corps de Méduse, tel un membre. Comme un rameau émanant d'un « tronc " gorgonéen pour se déployer, l'olivier apparaît comme une émanation de la Gorgone dont il prolonge et s'approprie graphiquement l'aspect fascinant et pétrifiant.

\section{Les Amazones face à l'olivier}

Le dossier iconographique des Amazonomachies ${ }^{100}$, topos mythique récurrent des invasions du territoire athénien ${ }^{101}$, renforce cette lecture de l'olivier. Remis au goût du jour au $v^{e}$ siècle comme un écho mythique aux Guerres médiques contre les barbares perses $^{102}$ en renforçant la présence de Thésée ${ }^{103}$, l'Amazonomachie semble un cadre pertinent pour analyser notre dossier. La présence de ce feuillage en épisème sur les boucliers des guerriers grecs prend ici toute sa dimension, puisque les Amazones 
envahissent l'Attique et mettent en péril la terre de l'olivier ${ }^{104}$ qui se retrouve de manière axiale sur les vases comme enjeu symbolique de cet affrontement ${ }^{105}$. Effectivement, plusieurs vases attiques à figures rouges mettent en scène Thésée, Pirithoos ou plus génériquement des hoplites armés d'un bouclier à épisème d'olivier face aux Amazones. Sur un cratère à volutes de New York (Fig. 17) ${ }^{106}$, l'olivier est doublement affiché en épisème sur les boucliers des deux combattants grecs centraux, assaillis par des Amazones à pied ou à cheval. L'olivier est ici un " épisème intérieur " : il apparaît de manière atypique sur la face interne du bouclier du guerrier armé en hoplite, entourant de manière circulaire le porpax, alors que l'épisème est usuellement apposé sur la face frontale de cette arme. Si l'épisème est "intérieur ", son exposition frontale en couronne, qui redouble la rotondité du bouclier, focalise le regard et opère un jeu visuel qui place le spectateur comme en «face » de ce guerrier : cet épisème est aussi redoublé par celui de son acolyte à terre, terrassé par une Amazone montée, retranché derrière un bouclier ourlé d'une couronne de feuillage en épisème dirigé face à l'ennemie ${ }^{107}$. Ces épisèmes semblent faire écho à l'identité athénienne de leurs porteurs. Le commentaire de la base Beazley qui identifie ce végétal comme du lierre («ivy leaves ») est visiblement erroné si l'on prête attention à la forme des feuilles ; mais il apparait surtout plus cohérent de figurer une couronne d'olivier comme symbole identitaire partagé d'Athènes, puisque les deux hoplites partagent leur épisème tout comme il partage leur combat: défendre la terre des oliviers face à l'invasion des Amazones. Sur le col du cratère, une Centauromachie, autre topos guerrier de lutte contre l'altérité et le désordre, répond à cette Amazonomachie.

Sur la frise supérieure d'un cratère en calice de Genève (Fig. 18) ${ }^{108}$, à nouveau, un Grec (Thésée ?) à la cuirasse ornée d'étoiles fait face à une Amazone infléchie, la hache à la main : le bouclier tenu par son bras gauche présente une couronne d'olivier sur sa face interne, celle qui est visible par le spectateur. Sur ses cnémides, des gorgoneia renforcent son aspect offensif et contribuent à construire son identité guerrière.

Sur un dinos de Londres (Fig. 19)109, Thésée et Pirithoos (nommés par des inscriptions) s'élancent vers une Amazone à terre, suivis par un combattant non identifié. Ce dernier porte, à son bras gauche, un bouclier dont il affiche, frontalement, la face intérieure : il est ourlé d'une couronne cette fois-ci clairement identifiable comme étant de l'olivier puisqu'elle porte des «fruits» de chaque côté des feuilles. De l'autre côté, un olivier portant des olives trône au centre de la mêlée, comme l'enjeu du combat - la terre d'Athéna. Les deux manières de représenter l'olivier se font écho ici; l'épisème, étroitement articulé à l'arbre symbolique de l'Athènes autochtone, prend toute sa dimension. Bien sûr, la figuration de l'olivier sur la face interne n'est pas équivalente à son inscription frontale, car le motif est destiné cette fois au spectateur et non plus à l'ennemi de la scène ${ }^{110}$; pourtant, le « jeu visuel » demeure et cet épisème d'olivier qui focalise le regard semble au service d'une «triangulation» entre le spectateurbanqueteur, l'hoplite et l'Amazone. En épisème intérieur ou extérieur, l'olivier apparait très étroitement associé au bouclier du guerrier sur les vases attiques, ce qui contribue à créer un faisceau de valeurs cohérent entre cette arme protectrice et offensive, à la fois identitaire et " éblouissante ", et l'arbre citoyen d'Athéna.

21 Un dernier vase représentant une Amazonomachie rappelle le cratère du peintre de Kékrops (Fig. 12 et 12bis) : sur ce cratère à volutes de Naples (Fig. 20) ${ }^{111}$, l'affrontement est représenté comme une mêlée entre les deux camps qui s'opposent par leurs postures et leurs costumes. À la droite du « duel central » entre un Grec (Thésée ?) et une Amazone 
infléchie, un guerrier se protège derrière son bouclier qui porte, en épisème, un gorgoneion entouré d'une couronne d'olivier dont on peut distinguer deux fruits ${ }^{112}$. À nouveau, un plant d'olivier qui porte des olives articule la scène et apporte une résonnance à cet épisème. Comme un écho entre mythe et histoire, une œnochoé du Louvre (Fig. 21) ${ }^{113}$ met en scène un hoplite qui s'élance, sa lance dressée, face à un homme clairement connoté de «barbare » par son accoutrement bariolé, et encadré de deux figures qui jouent sur la frontière graphique ténue entre Amazones et Perses. Dans ce duel central, la pilosité faciale de l'adversaire de l'hoplite nous porte à l'identifier comme une figure de Perse. L'hoplite, lui, porte un bouclier dont le motif central est une étoile entourée d'une couronne d'un feuillage qui, là encore, évoque l'olivier, puisque la défense d'Athènes est l'enjeu de cet affrontement; olivier qui est d'ailleurs repris par deux rameaux apposés sur le col de cette œnochoé. Entouré d'un motif de postes qui s'étage en cercle sur le pourtour du bouclier, l'olivier en couronne déploie son feuillage face au barbare envahisseur. Tous ces motifs, étoile, feuilles d'olivier, postes simulant des vagues, concourent, ensemble, à créer un épisème étincelant qui renvoie l'éclat du guerrier tout en « effrayant » l'ennemi.

Sans y voir un arbre "lithique "114, l'olivier semble s'insérer parfaitement dans le champ sémantique de l'épisème gorgonéen : brillant et miroitant d'un éclat divin, il retourne sa lumière face aux adversaires et devient ainsi, pour la Promachos et les citoyens athéniens, un arbre éblouissant qui repousse et protège. Comme un épisème de la cité d'Athènes.

\section{Liste des figures}

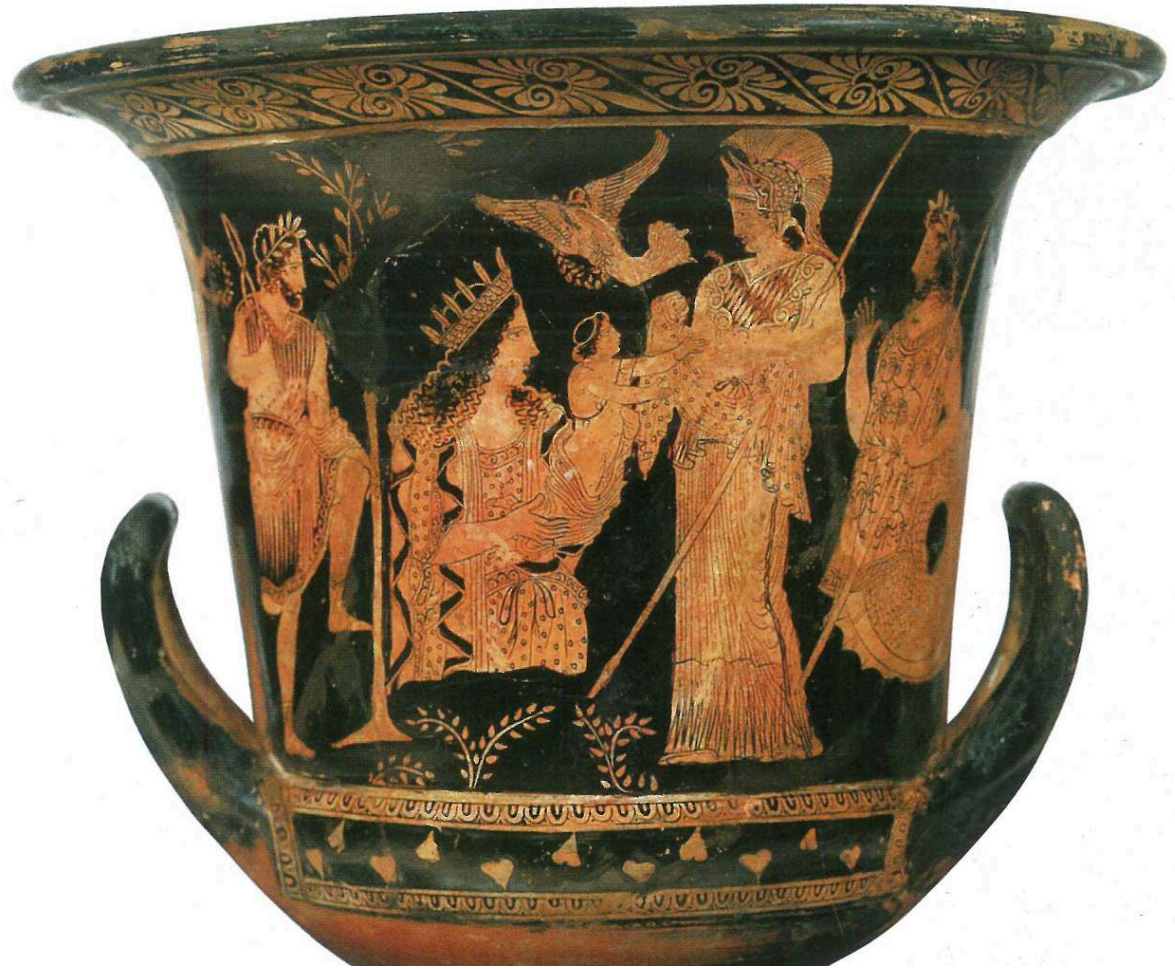

Fig. 1. Cratère en calice attique à f.r., Peintre de Talos (425-375 av. n.è.), Palerme, musée archéologique 2365, d'après ReEder (1995), p. 262-264, fig. 72. 


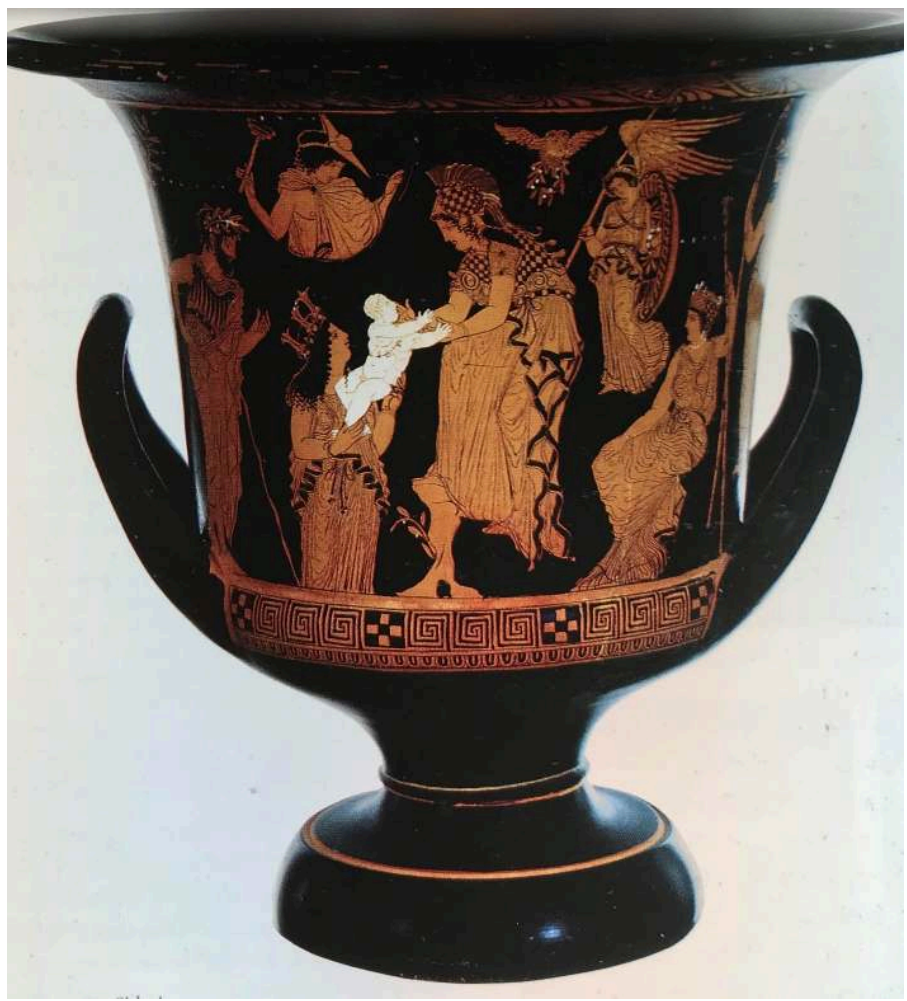

Fig. 2. Cratère en calice attique à f.r., Peintre de Nicias (425-375 av. n.è.), Richmond, Museum of Fine Arts 81.70, d'après https://www.vmfa.museum/piction/6027262-59120469/ (CC-BY-NC)

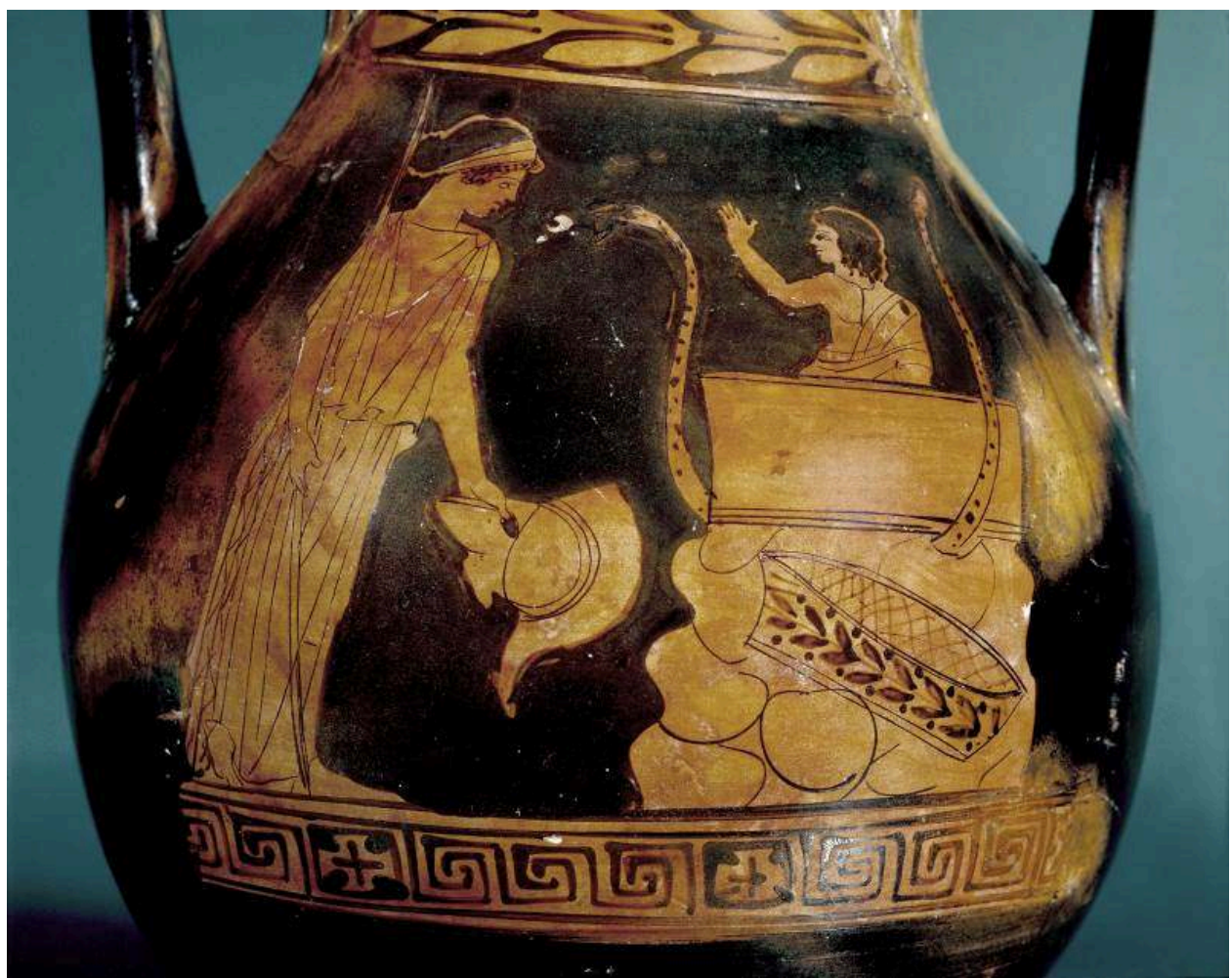

Fig. 3. Péliké attique à f.r., Peintre d'Érichthonios (450-400 av. n.è.), Londres, British Museum E372 (c) Trustees of the British Museum. 


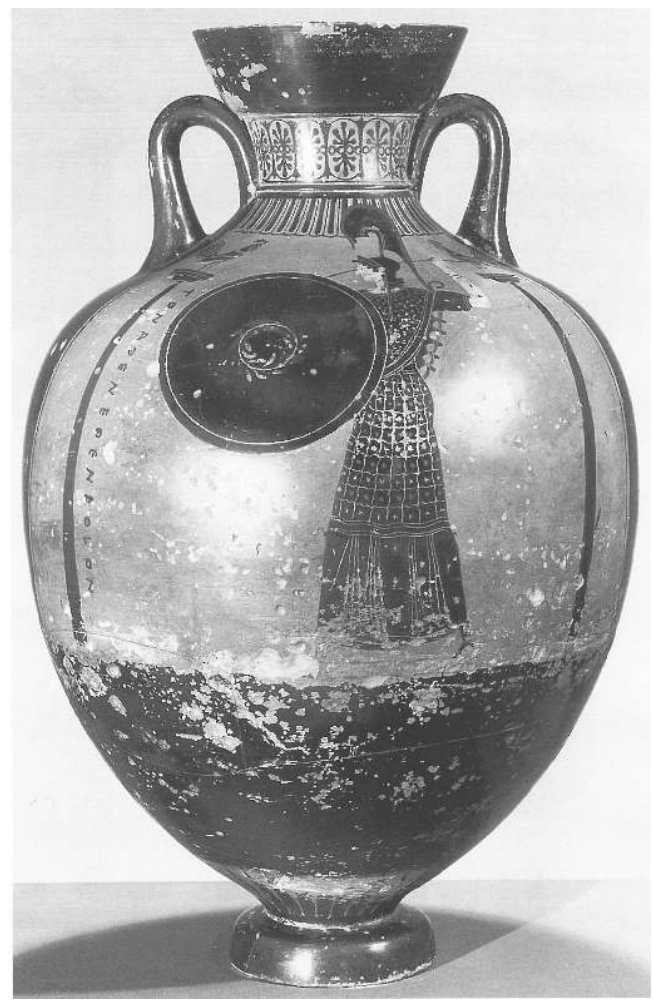

Fig. 4. Amphore panathénaïque, Berlin, Antikensammlung 3979 (ve siècle av. n.è.), d'après BENTz (1998), pl. 84.

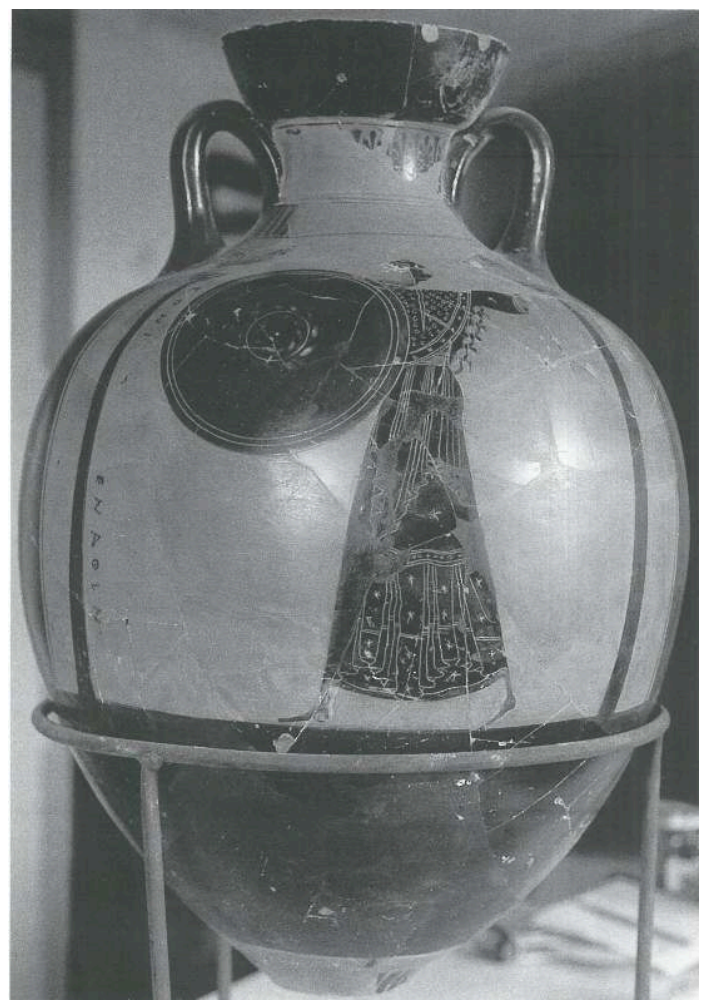

Fig. 5. Amphore panathénaïque, Athènes, Céramique PA700 (ve siècle av. n.è.), d'après bentz (1998), pl. 85. 


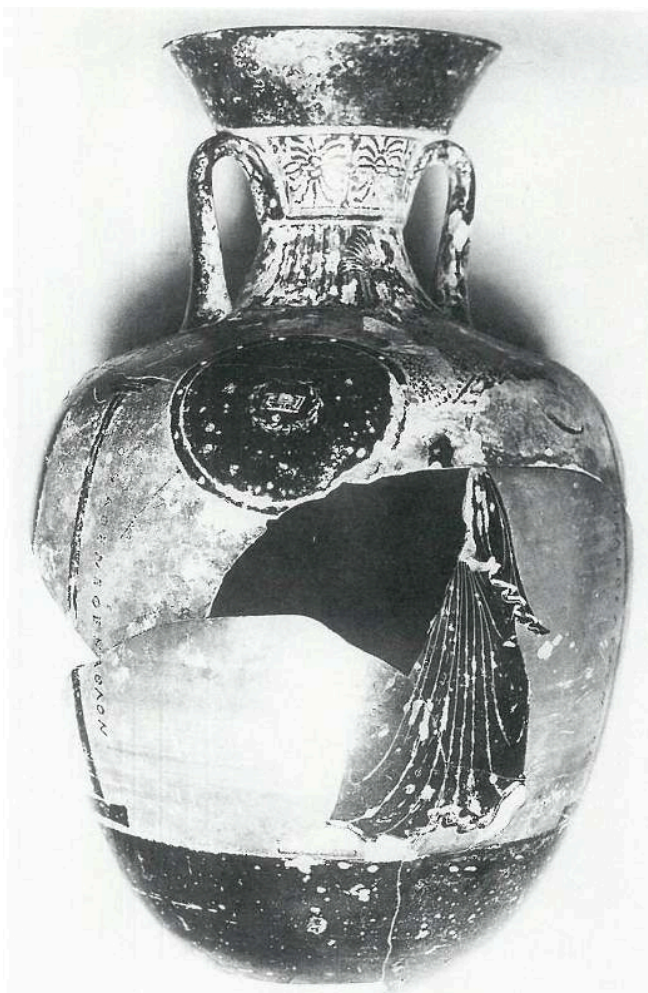

Fig. 6. Amphore panathénaïque, Balagrai, museum 2 (400-300 av. n.è.), d'après BENTZ, ESCHBACH (2001), pl. 10.1 .

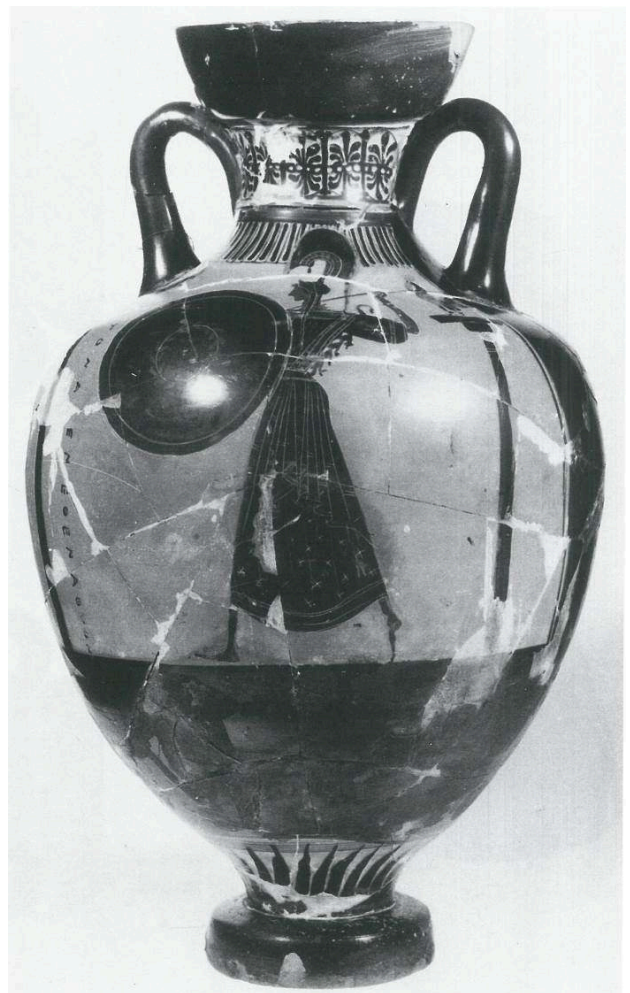

Fig. 7. Saint-Pétersbourg, Ermitage 17794 (500-450 av. n.è.), d'après bentz (1998), pl. 81. 

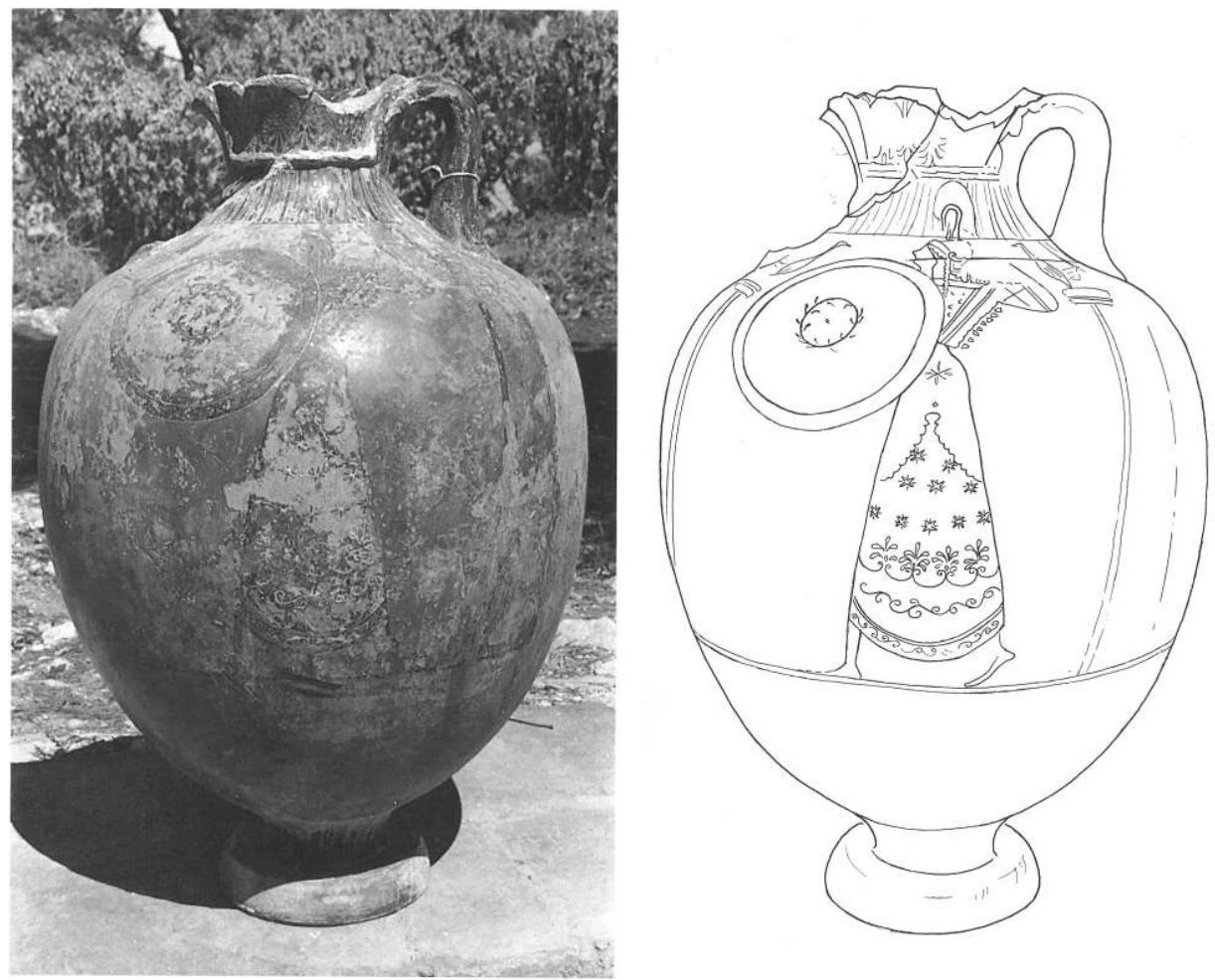

Fig. 8. Amphore panathénaïque, musée de Cyrène, d'après mAFFRE, FADL ALI (1993), p. 94 (Dessin de M.G. Froidevaux, CNRS/IRAA).

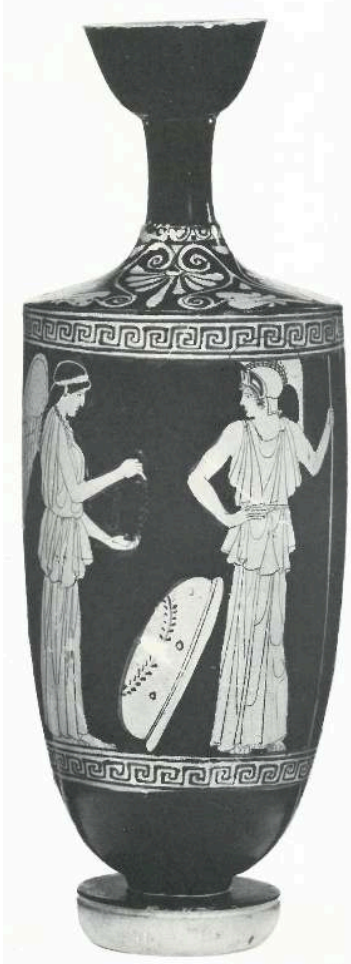

Fig. 9. Lécythe attique à f.r., Peintre d'Alkimakos (vers 450 av. n.è.), Hanovre, Kerster-Mus. 1968.93, d'après CVA Hanover I, pl. 44. 


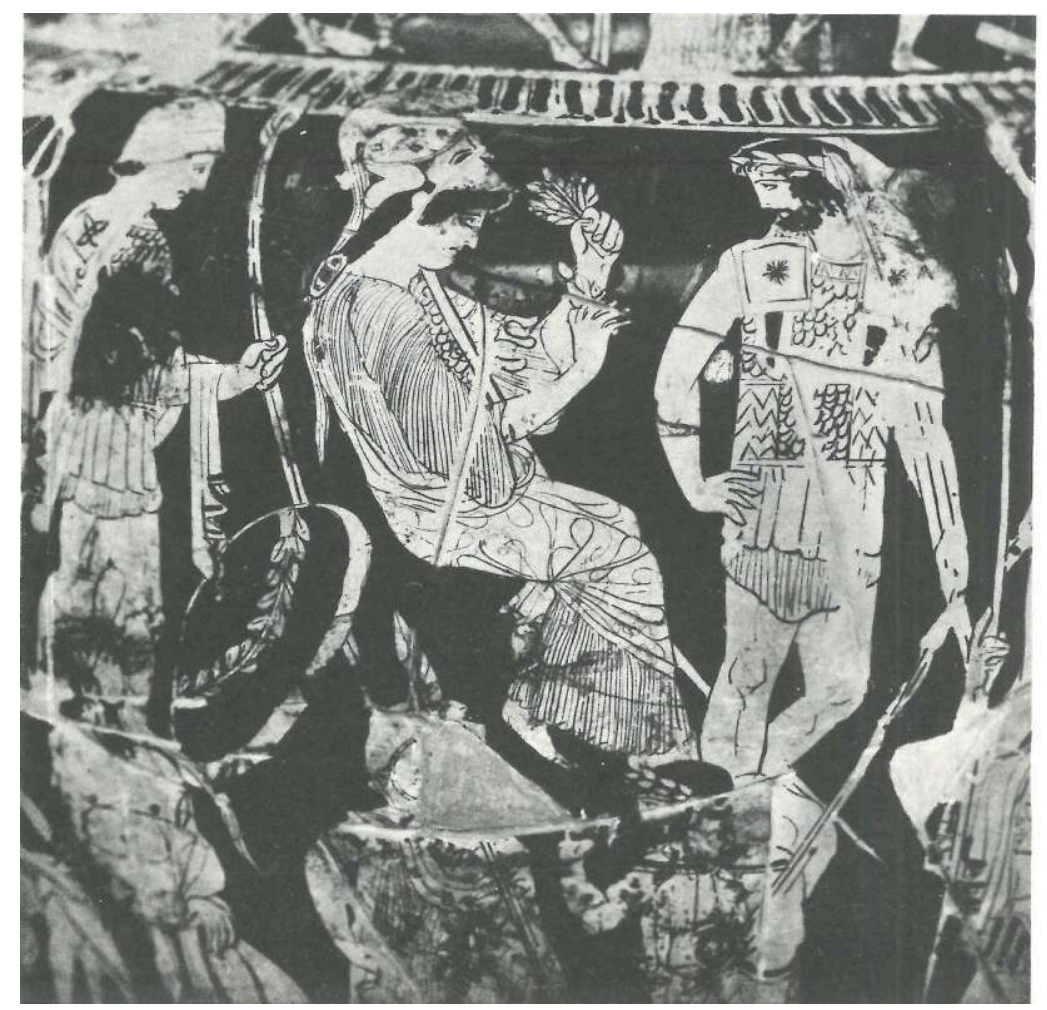

Fig. 10. Cratère à volutes attique à f.r., Peintre de Bologne 279 (475-425 av. n.è.), Ferrare, Museo nazionale di Spina 3031, d'après CVA Ferrara, Museo nazionale 1, pl. 10.4.

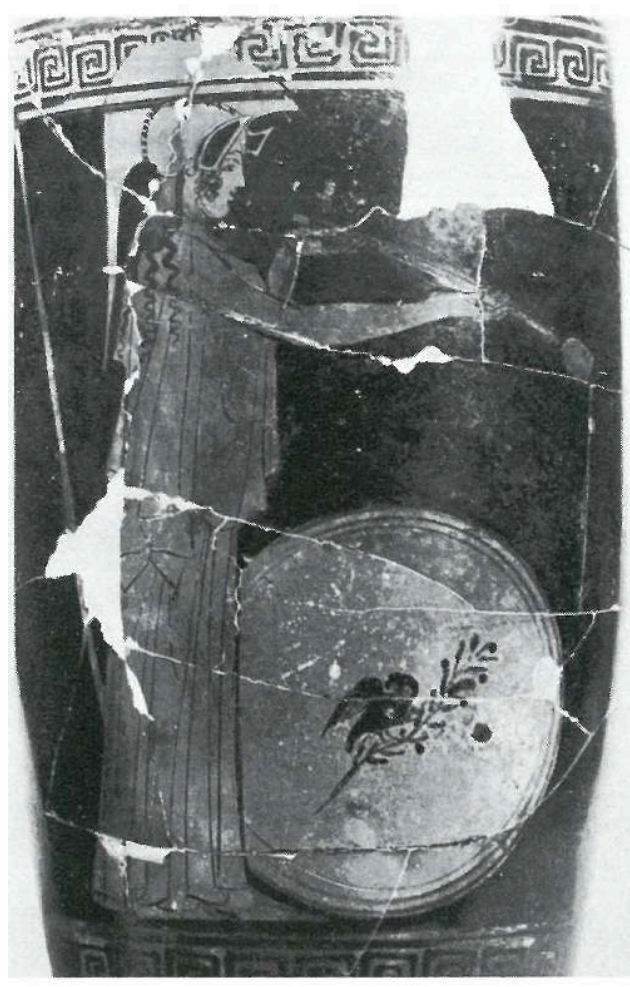

Fig. 11. Lécythe attique à f.r., (1 ${ }^{\text {re }}$ moitié du ve s. av. n.è.), Athènes, Musée de l'Acropole 2568, d'après G. DAux, «Chronique des fouilles 1969 » BCH 90 (1966), p. 741, fig. 1. 

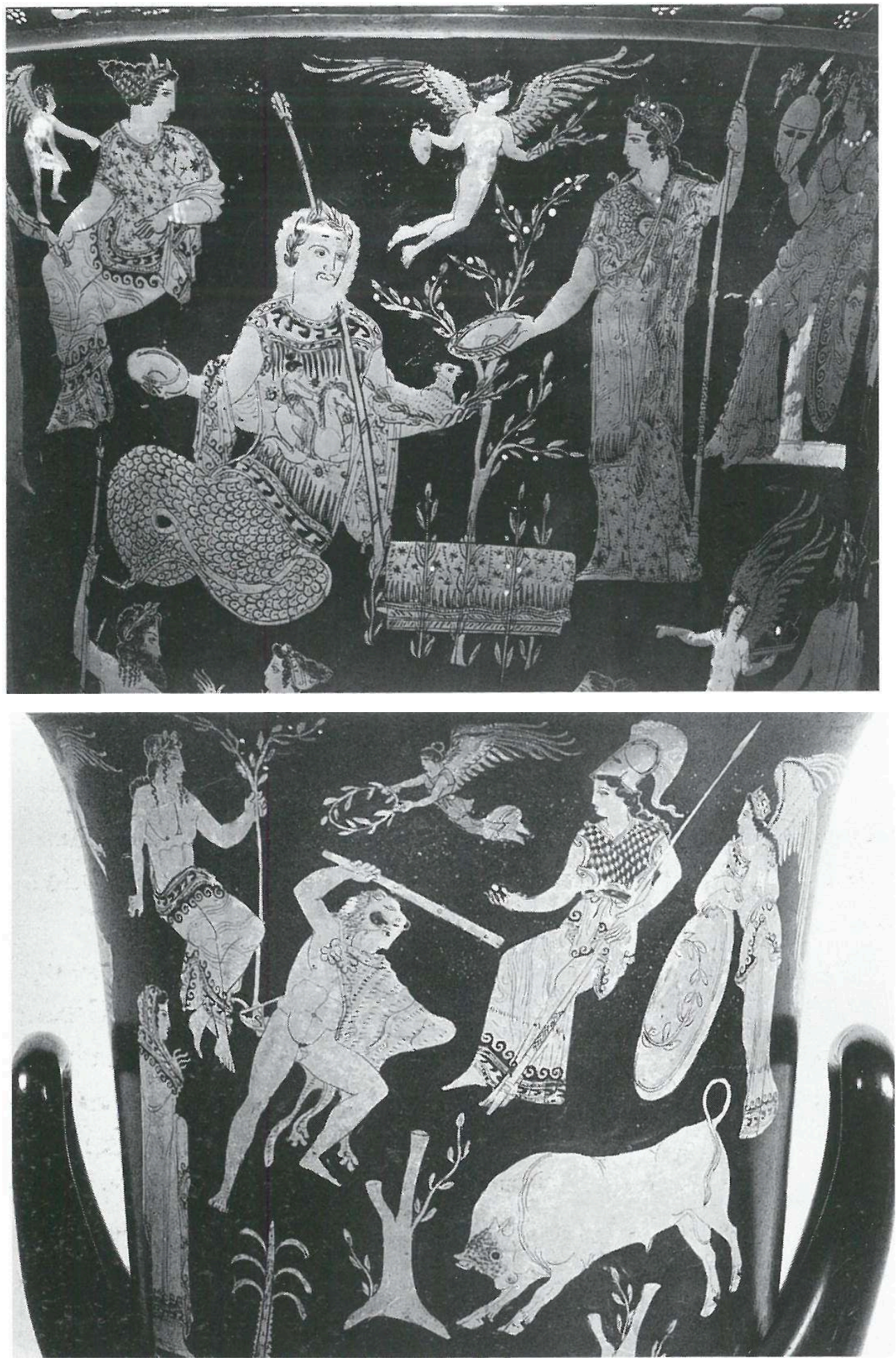

Fig. 12 et 13. Cratère en calice attique à f.r., Peintre de Kékrops (410-400 av. n.è.), Adolphseck, Schloss Fasanerie 77, d'après REEDER (1995), p. 264-266, fig. 73. 


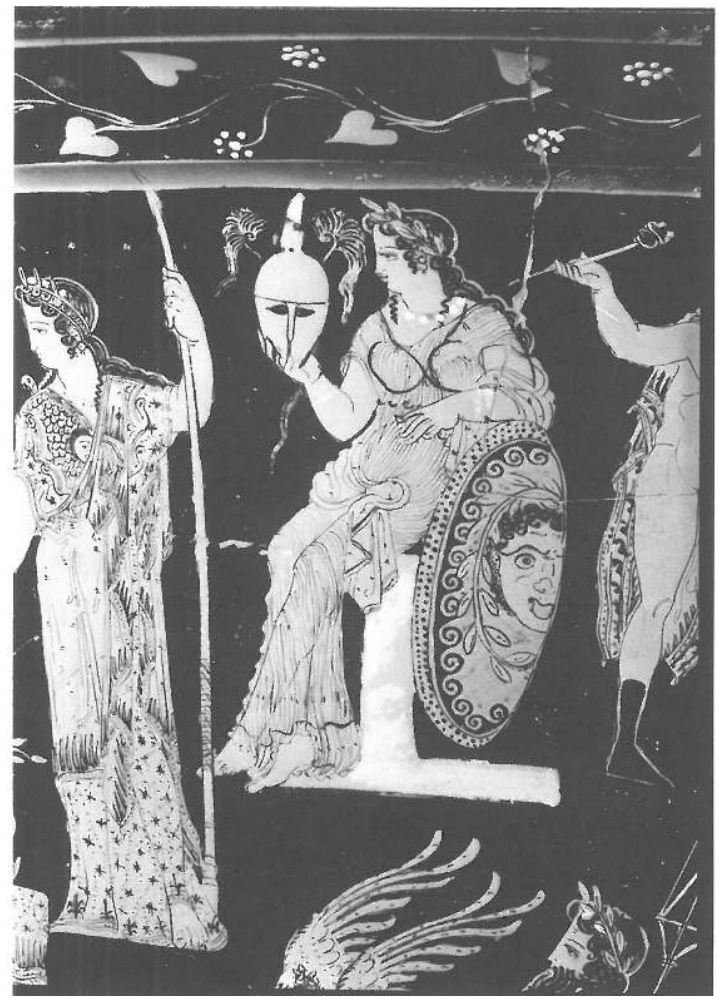

Fig. 12bis. Idem (détail), d'après sмıтн (2011), fig. 9.1.

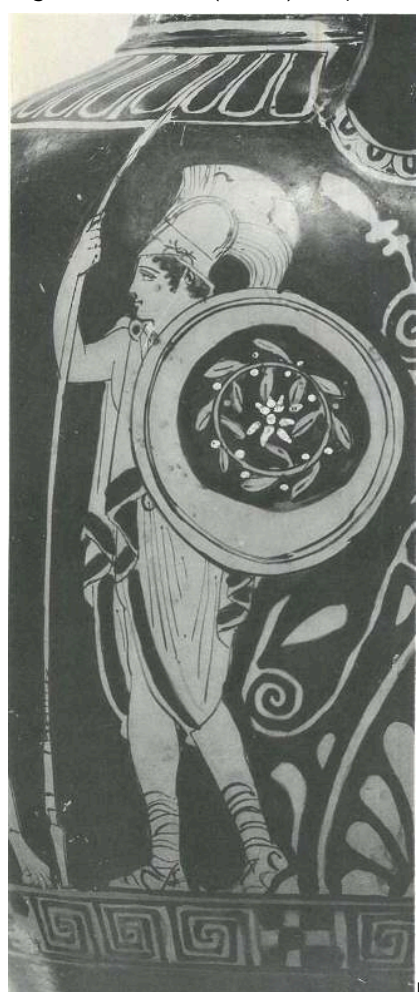

Fig. 14. Amphore attique à f.r., Peintre de Suessula (425-375 av. n.è.) New York, Metropolitan Museum 17.46.1, d'après G. RICHTER, L.F. HALL, Red-figured Athenian Vases in the Metropolitan Museum of Art, New Haven/London, 1936, pl. 162. 


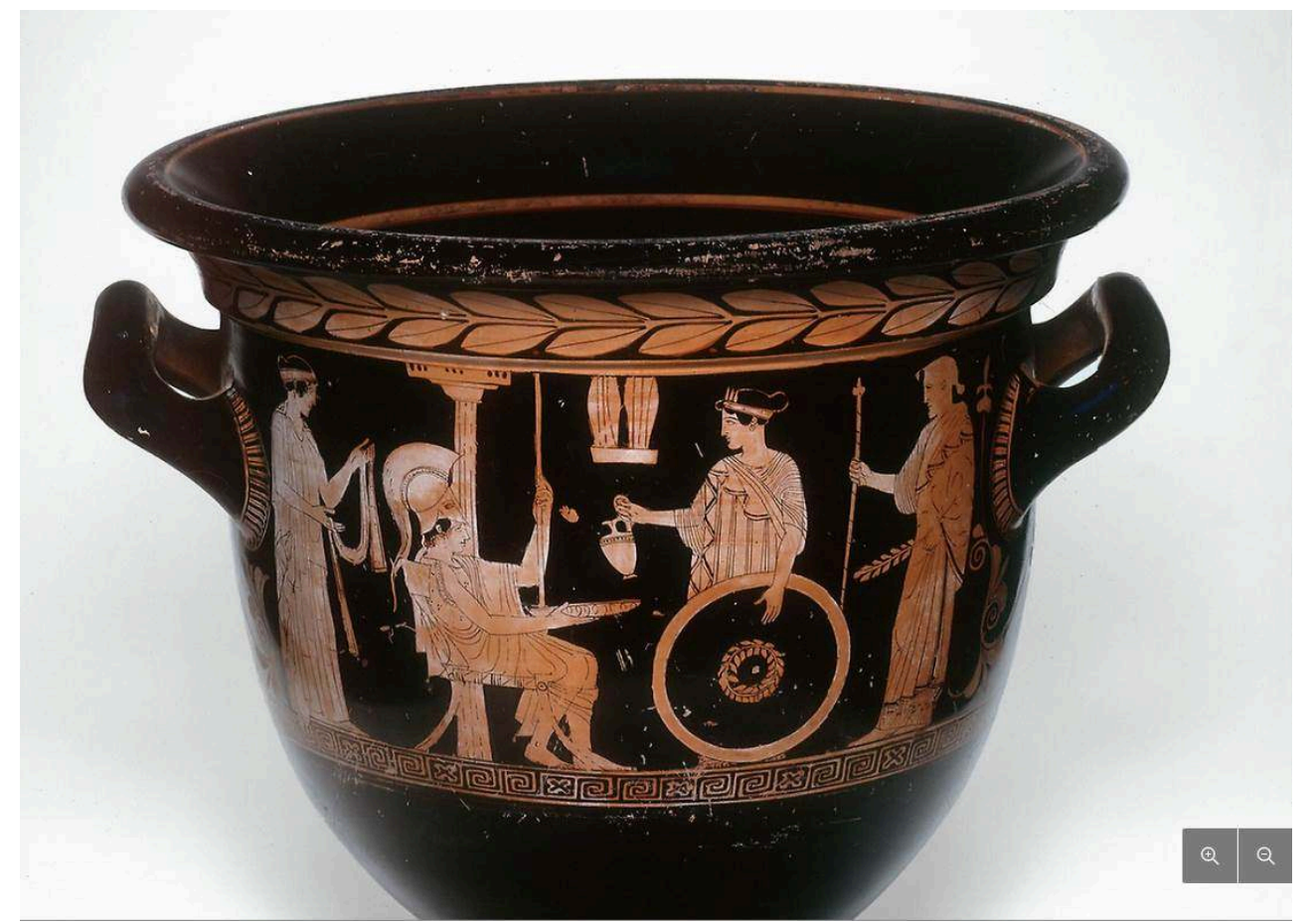

Fig. 15. Cratère en cloche attique à la manière du Peintre des Niobides (475-425 av. n.è.), Chicago, Art Institute 22.2197 d'après https://www.artic.edu/artworks/84551/bell-krater-mixing-bowl?q=niobides (CCO).

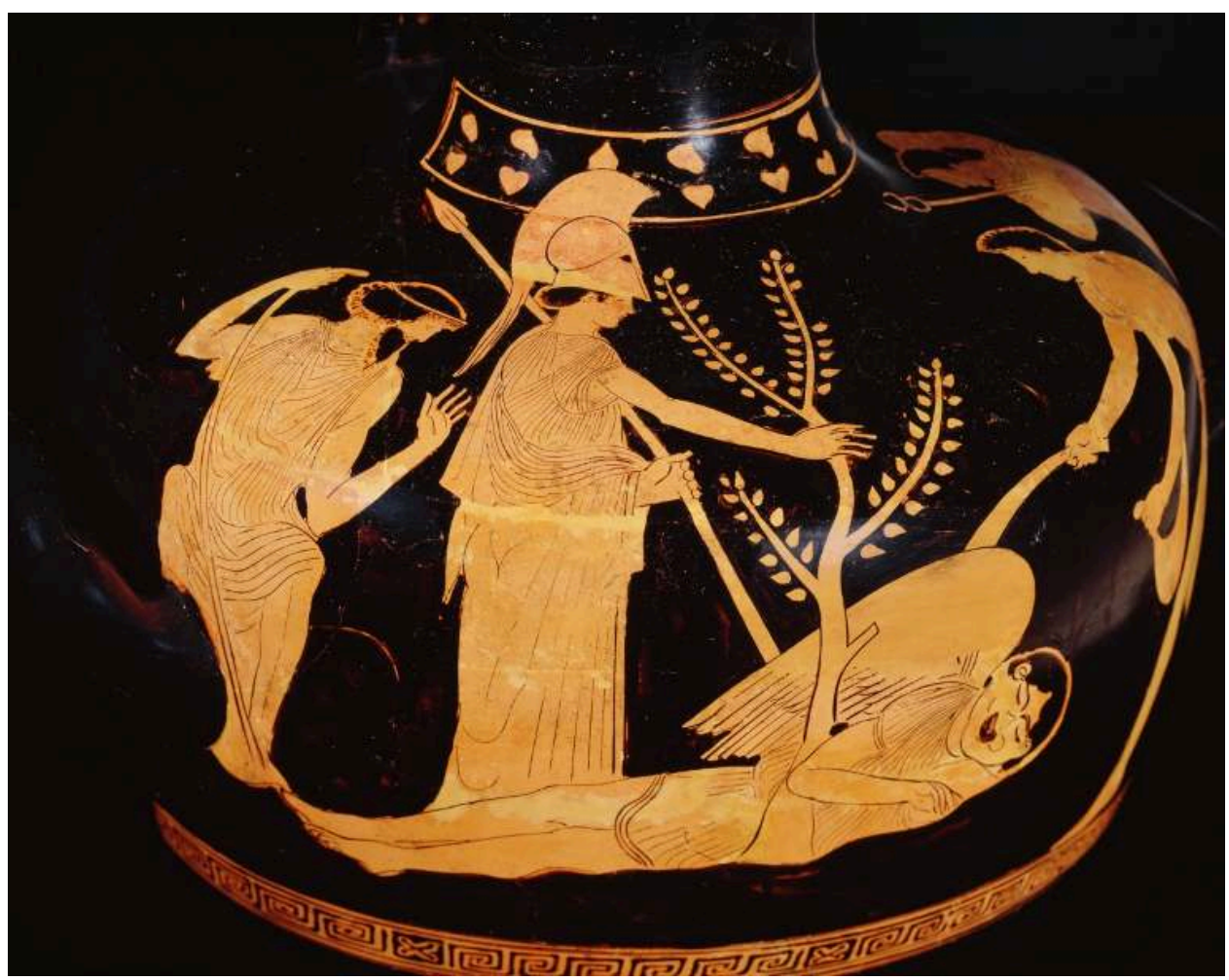

Fig. 16. Hydrie attique à f.r., Peintre de Nausicaa (450 av. n.è.), Richmond, Virginia museum 62.1.1, d'après https://www.vmfa.museum/piction/6027262-12958509/ (CC-BY-NC). 


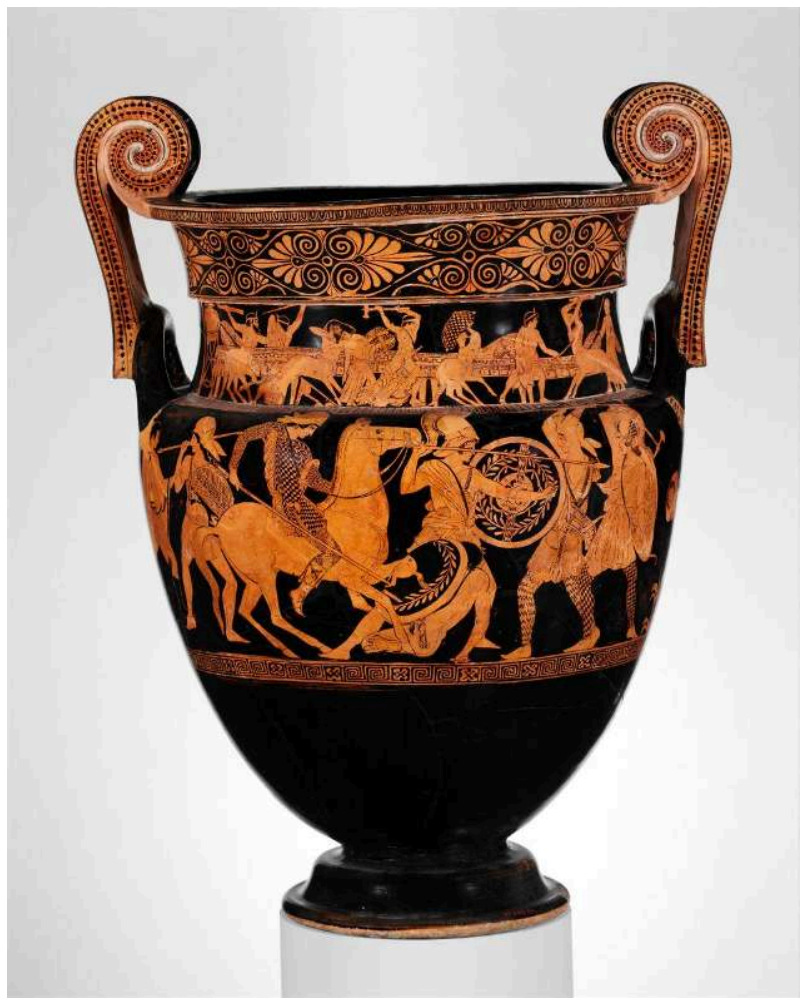

Fig. 17. Cratère à volutes attique à f.r., Peintre des satyres laineux (475-425 av. n.è.), New York, Metropolitan Museum 07.286.84, d'après https://www.metmuseum.org/art/collection/search/247964 (CCO)

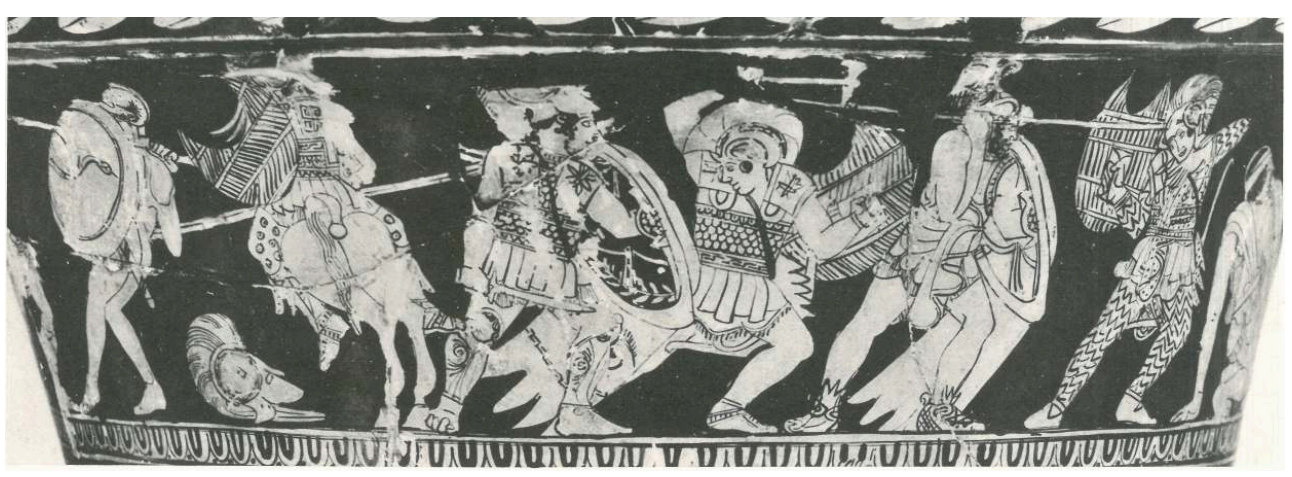

Fig. 18. Cratère en calice attique, Peintre de Genève (475-425 av. n.è.), Genève, Musée d'Art et d'Histoire MF238, d'après CVA Genève, musée d'art et d'histoire 1, pl. 14.3. 


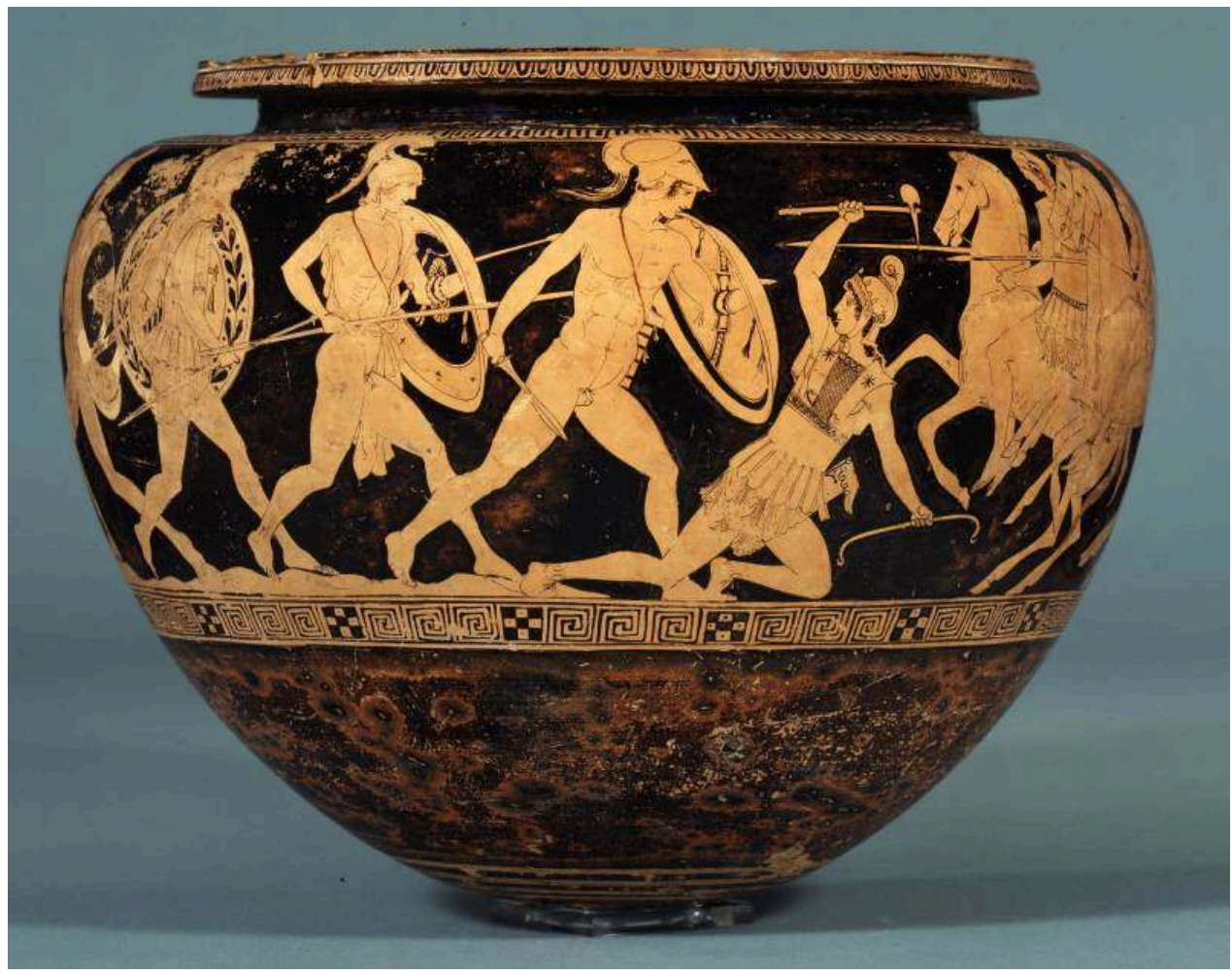

Fig. 19. Dinos attique à f.r., Groupe de Polygnotos (475-425 av. n.è.), Londres, British Museum, 1899.7-21.5, @Trustees of the British Museum.

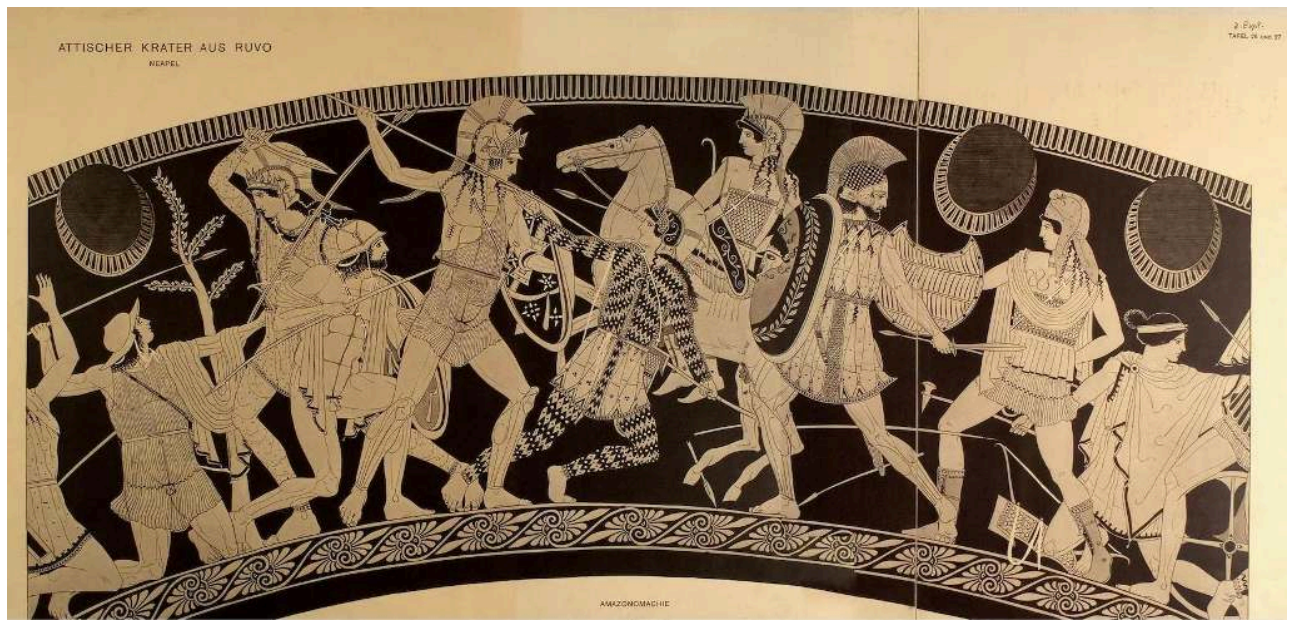

Fig. 20. Cratère à volutes attique à f.r., Peintre des Niobides (475-425 av. n.è.), Naples, Museo Archeologico Nazionale H2421, d'après A. FURTWANGLER, K. REICHHOLd, Griechische Vasenmalerei, Munich, 1904-32, pl. 26-27. 


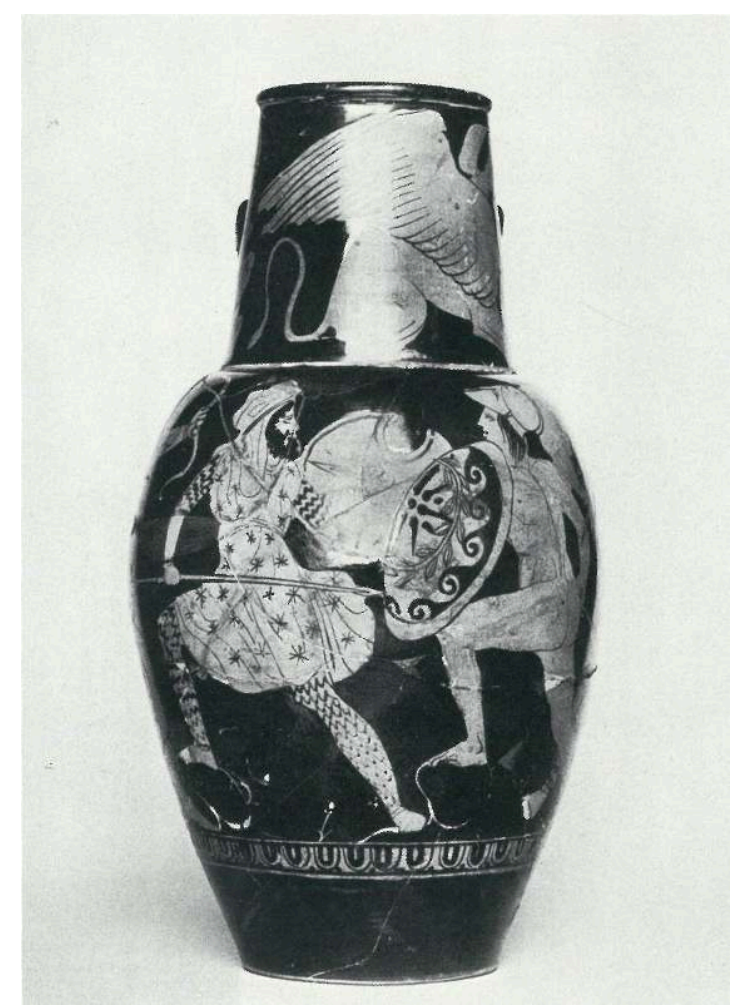

Fig. 21. Enochoé attique à f.r. à la manière du Peintre du taureau (450-400 av. n.è.), Paris, Musée du Louvre G571, d'après A. LEzzI-HAFTER, Der Schuwalow-Maler eine Kannenwerkstatt der Parthenonzeit, Mainz, 1976, pl. 161 c.

\section{BIBLIOGRAPHIE}

S. AMIGUES, Études de botanique antique, Paris, 2002.

M.-Cl. AMOURETTI, J.-P. BRUN (dir.), La production du vin et de l'huile en Méditerranée de l'âge du bronze à la fin duXvie siècle, Athènes/Paris, 1993.

M. BENTZ, Panathenaïsche Preisamphoren: Eine athenische Vasengattunugn und Hire Funktion vom 6.-4. Jahrhundert v. Chr, AK Beiheft 18 (1998).

M. BENTZ, N. ESCHBACH (éd.), Panathenaika: Symposion zu den panathenaïschen Preisamphore, Mayence, 2001.

A. BLANSHARD, « The Problems with Honouring Samos: an Athenian Document Relief and its Interpretation ", in Z. NEWBY, R. LEADER-NEWBY (éd.), Art and Inscriptions in the Ancient World, Cambridge, 2007, p. 19-37.

D. VON BOTHMER, Amazons in Greek art, Oxford, 1957.

M. BRETIN-CHABROL, C. LEDUC, « La botanique antique et la problématique du genre »,Clio. Femmes, Genre, Histoire 29 (2009), p. 205-223. 
M. BROUILLET, Des chants en partage. L'épopée homérique comme expérience religieuse, thèse de doctorat, EHESS, 2016 (https://halshs.archives-ouvertes.fr/tel-01503016/document).

P. BRULÉ, La fille d'Athènes. La religion des filles à Athènes à l'époque classique. Mythes, cultes et société, Paris, 1987.

-, « Le polythéisme en transformation : les listes des dieux dans les serments internationaux en Grèce antique ( $\mathrm{v}^{\mathrm{e}}-\mathrm{II} \mathrm{e}^{\mathrm{e}}$ siècle av. J.-C.) ", inN. BELAYCHE, P. BRULÉ, G. FREYBURGER, Y. LEHMANN, L. PERNOT, F. PRost (éd.), Nommer les dieux. Théonymes, épithètes, épiclèses dans l'Antiquité, Turnout, 2005, p. 143173.

Cl. CALAmE, Thésée et l'imaginaire athénien. Légende et culte en Grèce antique, Paris, 2018.

M. CARASTRO, « Fabriquer du lien en Grèce ancienne : serments, sacrifices, ligatures », in Serments et paroles efficaces, Métis N.S. 10 (2012), p. 79-107.

G.H. CHASE, The Shield Devices of the Greeks in Art and Literature, Chicago, 1979.

L. CHAZALON, « L'arbre et le paysage dans la céramique attique figurée archaïque », AION 2 (1995),

p. 103-131.

C. CHIESA, Sémiosis - Signes - Symboles. Introduction aux théories du signe linguistique de Platon et d'Aristote, Berne/Berlin, 1991.

O. CURTY, L'huile et l'argent. Actes du colloque tenu à Fribourg du 13 au 15 octobre 2005, Paris, 2009.

S. DARTHOU, Poséidon en terre d'Athènes, un dieu entre séisme et fondation (thèse, dir. M. DETIENNE), Paris, EPHE, 2000, consultable en ligne : https://tel.archives-ouvertes.fr/tel-00825331.

-, « Retour à la terre : fin de la geste d'Érechthée »,Kernos 18 (2005), p. 69-83.

-, « Éris dans la cité. Quelques réflexions sur les ‘cosmogonies' politiques », Mètis N.S. 6 (2008), p. 269-285.

S. DARTHOU, N. STRAWCZYNSKI,

« Naissance, reconnaissance, légitimation : les gestes de la filiation dans la céramique attique », Actes du colloque Gestuelles, attitudes, regards. L'expression des corps dans l'imagerie antique (2004), Rennes, 2006, p. 49-59.

G. DAUX, «Sur quelques inscriptions. Anthroponymes, concours à Pergame, serment éphébique », REG 84 (1971), p. 350-383.

M. DETIENNE, « L'olivier : un mythe politico-religieux », RHR 3 (1970), p. 5-23.

-, L'Écriture d'Orphée, Paris, 1989.

M. DETIENNE, J.-P. VERNANT, Les Ruses de l'intelligence. La mètis des Grecs, Paris, 2009.

M. DETIENNE, «De l'efficacité en raison pratique : Approches comparatives », in Serments et paroles efficaces, Métis N.S. 10 (2012), p. 349-361.

P. DEVAMBEZ, s.v. Amazones, LIMC I (1981), p. 586-653.

N. DIETRICH, Figur ohne Raum? Bäume und Felsen in der attischen Vasenmalerei des 6. und 5. Jahrhunderts v. Chr., Berlin/New York, 2010.

F. DINGREMONT, « Du sol phéacien au lit nuptial. Un arbre enraciné dans l'Odyssée », Poétique 148.4 (2006), p. 435-453.

C. FLAMENT, Le monnayage en argent d'Athènes. De l'époque archaïque à l'époque hellénistique (c. 550 c. 40 av. J.-C.), Louvain-la-Neuve, 2007. 
L. FOXHALL, Olive Cultivation in Ancient Greece : Seeking the Ancient Economy, Oxford, 2007.

F. FRONTISI-DUCROUX, Du masque au visage. Aspects de l'identité en Grèce ancienne, Paris, 2012.

F. FRONTISI-DUCROUX, J.-P. VERNANT, Dans l'œil du miroir, Paris, 2005.

A. FURTWANGLER, K. REICHHOLD, Griechische Vasenmalerei: Auswahl hervorragender Vasenbilder, München, 1904-1932.

L. GOURMELEN, Kékrops, le Roi-Serpent. Imaginaire athénien, représentations de l'humain et de l'animalité en Grèce ancienne, Paris, 2004.

A. GRAND-CLÉMENT, « Dans les yeux d'Athéna Glaukôpis »,ARG 12.1 (2010), p. 7-22.

-, La fabrique des couleurs. Histoire du paysage sensible des Grecs anciens (VIII - début du ve siècle avant notre ère), Paris, 2011.

-, « Des couleurs et des sens : percevoir la présence divine », Kernos suppl. 31 (2017), p. 43-61.

M. HALM-TISSERANT, « Le Gorgoneion, emblème d'Athéna. Introduction du motif sur le bouclier et l'égide », RA N.S. Fasc. 2 (1986), p. 245-278.

-, «Exo - entos - de l'ambiguïté des portes et des fenêtres dans la peinture de vases grecs »,REA 97 (1995), $\mathrm{n}^{\circ} 3-4$, p. 473-503.

B. Holtzmann, L'Acropole d'Athènes. Monuments, cultes et histoire du sanctuaire d'Athéna Polias, Paris, 2003.

A. JACQUEMIN, Les Épisèmes de boucliers, Mémoire de Maîtrise non publié, Paris IV, 1973.

D. JAILLARD, «Les fonctions du mythe dans l'organisation spatiale de la cité », Kernos 20 (2007),

p. $131-152$.

F.B. JoHnson, « An Owl Skyphos », in G. MYLonAs (éd.), Studies Presented to David Moore Robinson on His Seventieth Birthday, vol. 2, St. Louis, 1953, p. 96-105.

-,« A Note onOwl Skyphoi »,AJA 59 (1955), p. 119-124.

C. JUBIER, A.-F. LAURENS, « Boucliers en image et images de bouclier, effets de réel », in P. SAUZEAU, Th. VAN COMPERNOLLE(éd.),Les armes dans l'Antiquité: de la technique à l'imaginaire, Montpellier, 2007, p. $108-120$.

N. KEI, « TheFloral Aesthetics of Attic Red-figured Pottery: Visual Adornment and Interplay between Ornament and Figure », in C. LANG-AUINGER, E. TRINKL (éd.), ФYTA KAI ZSIA. Pflanzen und Tiere auf Griechischen Vasen, Vienna, 2016 (CVA Österreich Beiheft 2), p. 271-280.

—, « Poikilia et kosmos floraux dans la céramique du vi et du V siècle », in L. BODIOU,

Fl. GHERCHANOC, V. HUET, V. MEHL(éd.), Parures et artifices : le corps exposé dans l'Antiquité, Paris, 2011, p. 233-250.

-, L'esthétique des fleurs : kosmos, poikilia et kharis dans la céramique attique(à paraître chez De Gruyter).

E. KUNZE-GÖTTE, Myrte als Attribut und Ornament auf attischen Vasen, Kilchberg, 2006.

D.J. KYLE, « Gift and Glory: Panathenaic and Other Greek Athletic Prizes », in J. NEILS (éd.), Worshipping Athena: Panathenaia \& Parthenon, Madison (W.), 1996, p. 106-136.

P. LAFARGUE, «Le pais amphithalês : l'autre enfant d'Athéna », Mètis N.S.15 (2017), p. 203-229.

C.L. LAWTON, Attic Document Reliefs. Art and Politics in Ancient Athens, Oxford, 1995. 
C. LEDUC, « Athéna, l'olivier et la problématique des sexes ", in Les rapports sociaux de sexes: problématique, méthodologie, champs d'analyse, Actes de la table ronde internationale des 24-2526 novembre 1987, IRESCO cahier $\mathrm{n}^{\circ} 7$ (1988),p. 59-68.

-, «Rêveries sur la Vierge à l'olivier », in M.M. MACTOux, E. GENY (dir.), Mélanges Pierre Lévêque. Religion, Annales littéraires de l'Université de Besançon, 1990, p. 259-275.

-, « Poésie et politique dans le mythe de l'autochtonie athénienne », Itaca 22 (2006), p. 13-22 [repris dans L. BODIOU, V. MEHL (dir.), La religion des femmes en Grèce antique. Mythes, cultes et société, Rennes, 2009, p. 161-172].

-, « L'énigmatiqueKourotrophos et l'olivier de l'Acropole », in L. Bodiou, V. MEHL et al. (dir.), Chemin faisant. Mythes, cultes et société. Mélanges Pierre Brulé, Rennes, 2009, p. 145-165.

-, « Autochtonie et maternité à Athènes (époques archaïque et classique) », Cahiers « Mondes anciens »6 (2015),p. 1-17.

F. LISSARRAGUE, « Comment citer en image ? Quelques variations grecques » in C. DARBO-PESCHANSKI (éd.), La Citation dans l'Antiquité, Grenoble, 2004, p. 103-108.

-, « De l'image au signe », Les Cahiers du Centre de Recherches Historiques [En ligne] 37 (2006).

-, « Looking at Shield Devices: Tragedy and Vase Painting », in C. KRAUS, S. GOLDHILL, H.P. FOLEY, J. ELSNER (éd.), Visualizing the Tragic. Drama, Myth, and Ritual in Greek Art and Literature. Essays in honour of Froma Zeitlin, Oxford, 2007, p. 151-164.

-, « Le temps des boucliers », Images Re-vues [En ligne], Hors-série 1 (2008).

-, « Vases grecs : à vos marques », in A. TSINGARIDA(éd.),Shapes and uses of Greek Vases, Bruxelles, 2009, p. 237-249.

-, « Corps à corps : épisèmes anthropomorphiques dans la céramique attique », in D. BOSCHUNG, A. SHAPIRO, F. WASCHECK (éd.), Bodies in Transition. Dissolving the Boundaries of Embodied Knowledge, Paderborn, 2015 (Morphomata, 23), p. 11-31.

-, « Armure et ornement dans l'imagerie attique », in N. DIETRICH, M. SQUIRE(éd.), Ornament and Figure in Graeco-Roman Art. Rethinking Visual Ontologies in Classical Antiquity, Berlin/New York, 2017, p. 129-141.

F. LISSARRAGUe, P. SCHMITT-PANTEL (2009), « Amazones, entre peur et rêve », in G. LEDUC(éd.), Réalité et représentation des Amazones, Paris, 2009, p. 43-64.

C. Lochin, «Athéna et Kékrops : une scène de culte sur l'Acropole ", in Agathos Daimôn, Mythes et Cultes. Études d'iconographie en l'honneur de Lilly Kahil, BCH suppl. 38 (2000), p. 323-331.

N. LORAUX, Les Enfants d'Athéna. Idées athéniennes sur la citoyenneté et la division des sexes, Paris, 1990.

—, Né de la terre. Mythe et politique à Athènes, Paris, 1996.

J.-J. MAFFRE, M. FADL ALI, « Une nouvelle amphore panathénaïque découverte à Barca, en Cyrénaïque », RA N.S. Fasc. 1 (1993), p. 91-100.

A. MAYOR, Les Amazones : quand les femmes étaient les égales des hommes, VIII siècle av. J.-C. - Ir siècle apr. J.-C., Paris, 2017.

P. MONBRUN, « La chouette-hoplite d'Athéna et la Crète des archers : les 'dessous' d'une allergie réciproque », REA 109.2 (2007), p. 559-581.

E. MONTANARI, Il mito dell'autochtonia. Lince di una dinamica mitico-politica ateniese, Roma, 1981. 
M.N. NAGLER, « Dread Goddesses Revisited », in S.L. SCHEIN (éd.), Reading the Odyssey. Selective Interpretive Essays, Princeton, 1996, p. 141-162.

J. NEILS, Goddess and Polis: The Panathenaic Festival in Ancient Athens, Hanover/Princeton, 1992.

-, Worshipping Athena: Panathenaia \& Parthenon, Madison, 1996.

J.H. OAKLEY, «A Calyx-Krater in Virginia by the Nikias Painter with the Birth of Erichthonius », AK 30 (1987), p. 123-130.

E. PAMPANAY, « Divinités ou personnifications ? L'exemple de deux en-têtes de traités d'alliance athéniens ", Kentron 3 (2017), p. 37-54.

A. PARADISO, «Sur l'altérité grecque, ses degrés, ses états », RHR 209.1 (1992), p. 55-64.

C. PÉLÉKIDIS, Histoire de l'éphébie attique, Paris, 1962.

H.D. REEDER (éd.), Pandora : Women in Classical Greece, Baltimore/Princeton, 1995.

P. J. RHODES, R. OSBORNE (éd.), Greek Historical Inscriptions, 404-323 BC, Oxford, 2003.

L. ROBERT, Études épigraphiques et philologiques, Paris, 1938.

P. SIEWERT, « The Ephebic Oath in Fifth-Century Athens », JHS 97 (1977), p. 102-111.

A. SMETS, « Groupes chronologiques des amphores panathénaïques inscrites », AC 5.1 (1936), p. 87 104.

A.C. SMITH, Polis and Personification in Classical Athenian Art, Leiden/Boston, 2011.

A. STEWART, «Imag(in)ing the Other: Amazons and Ethnicity in Fifth-Century Athens », Poetics Today 16.4 (1995), p. 571-597.

R. STURM, Amazonen in der antiken Vasenmalerei: die Bedeutung des Bildmotivs der kriegerischen Frau in der alten Töpferkunst, Hamburg, 2017.

R. TOUZÉ, Des couronnes végétales en Grèce ancienne : entre matière et imaginaire (dir. P. BRULÉ, Université européenne de Bretagne, 2012, thèse de doctorat non publiée, je remercie vivement l'auteur de m'avoir permis sa consultation).

J.-P. VERNANT, La Mort dans les yeux. Figures de l'Autre en Grèce ancienne, Paris, 1985a [repris dans Euvres. Religions. Rationalités. Politique, Paris, 2007, t. 2, p. 1809-1823].

-, Mythe et pensée chez les Grecs, Paris, 1985b [repris dans Euvres. Religions. Rationalités. Politique, Paris, 2007, t. 1, p. 245-611].

-, L'Individu, la mort, l'amour. Soi-même et l'autre en Grèce ancienne, Paris, 1989 [repris dans Euvres. Religions. Rationalités. Politique, Paris, 2007, t. 2, p. 1305-1471].

-, L'Univers, les dieux, les hommes, Paris, 1999 [repris dans Euvres. Religions. Rationalités. Politique, Paris, 2007, t. 1, p. 13-152].

P. VIDAL-NAQUET, Le Chasseur noir, Paris, 1981.

G.A. XENIS, Scholia vetera in Sophoclis Oedipum Coloneum, Berlin/Boston, 2018.

D. yatromanolakis (éd.), An Archaeology of Representations: Ancient Greek Vase-Painting and Contemporary Methodologies, Athènes, 2009. 


\section{NOTES}

1. Par exemple, Apollod., Bibl. III, 14, 1 ; Plut., Thém., 19, 3 ; Pausanias, I, 24, 5 ; I, 26, 5 ; I, 27, 1 ; Hdt., VIII, 55 ; Ael. Aristide, Disc. panath., 40-42 ; Ovide, Métam. VI, 76 ; VI, 80-82 ; Strabon, VIII, 1, 2. L'olivier est central au milieu des deux protagonistes sur le fronton ouest du Parthénon (HOLTZMANN [2003], p.139-141). Sur ce mythe de fondation, voir DARTHOU (2000), notamment p. 175-216 et pour l'Acropole rocailleuse, ibid., p. 142-143; sur l'eris, voir DARTHOU (2008). Sur l'olivier, voir l'article fondateur de DETIENNE (1970).

2. Sur cette primauté, Eur., Ion, 1433-1435 ; Eur., Troy., 800-803 ; Hygin, Fables, 164 ; Soph., OC, 694-697 ; Hdt., V, 82.

3. Récurrence de l'emploi du verbe phuô : Apollod., Bibl. III, 14, 1 ; Philochore, 328 F 93 (JACOBY).

4. Par exemple, Soph., OC, 700 ; Euripide, IT, 1101 ; Apollod., Bibl. III, 14, 1.

5. Théophr., Rech. plantes III, 2, 1; I, 4, 1. Voir FOXHALL (2007); AMOURETTI - BRUN (1993); LEDUC (1990) et (2016) ; TOUZÉ (2012), particulièrement p. 100-101 (je remercie vivement l'auteur de m'en avoir permis la consultation).

6. Artémidore, Oneir. IV, 57 ; Euripide, Ion, 1435-1436 ; Esch., Perses, 616-617 ; Porph., Antre des nymphes, 32 et 33.

7. Pline, HN XVI, 241 ; Théophr., Rech. plantes IV, 13, 2 et 5.

8. Nonnos, Dion. XL, 490.

9. Plut., Propos de table, 8, 2 (723f).

10. I, 27, 2 ; Hdt., VIII, 55 ; Théophr., Rech. plantes II, 3, 2 (sans localiser à Athènes).

11. Pour la définition de la mètis, DETIENNE - VERNANT (2009), p. 10 et, pour les rapports entre Athéna et la mètis, ibid, p. 169-177.

12. Platon, Critias, 109c, indique qu'Athéna et Héphaïstos partagent la philotechnia.

13. Elle se présente, dans les vers d'Eschyle (Eum., 910-912), comme un "berger des plantes » (phitupoimenos) et utilise des métaphores végétales.

14. Soph., OC, 701 (paidotrophos) ; Hhom. Héph., 1-3 ; Plut., Thém., 19, 4 : « On dit en effet que ceuxci (les anciens rois d'Athènes), s'évertuant à détourner les citoyens de la mer et les habituer à vivre, non de la navigation, mais de l'agriculture, avaient répandu le récit selon lequel Athéna, disputant le pays à Poséidon, avait montré l'olivier sacré aux juges et remporté ainsi la victoire. » Voir DETIENNE (1970) et (1989), p. 81 ; MONTANARI (1981), p. 44 ; LEDUC (1990).

15. Qui a reçu des appellations successives en fonction des différents fondateurs : « Kékrops [...] Aktè [...] Atthis [...] Poséidonia et Athènes des dieux éponymes » (Strabon, IX, 1, 18).

16. Stèle d'Acharnes (350-330 av. n.è.), publiée in RHODES - OSBORNE (2003), $\mathrm{n}^{\circ} 88$;ROBERT (1938), p. 296-307 ; PÉLÉKIDIS (1962), p. 77-78, 113 ; DETIENNE (1970), p. 31 ; DAUX (1971), p. 370-383 ; SIEWERT (1977), p. 102-111 ; VIDAL-NAQUET (1991), p. 144-149; 151-176 ; BRULÉ (1987), p. 33-34. Sur les dieux invoqués dans les serments, voir BRULÉ (2005) ; sur la notion d'efficacité du serment, voir DETIENNE (2012). Sur le lien, CARASTRO (2012). Pour les mentions littéraires, voir par exemple Lycurgue, C. Léocrate, 77 et Pollux, VIII, 105 (sans mention d'olivier néanmoins).

17. Il « tient ensemble la démocratie » comme l'expose Lycurgue, C. Léocrate, 79.

18. Plut., Alcib., 15, 7-8 : «Cependant il conseillait aux Athéniens de s'attacher aussi à la terre et de confirmer par des actes le serment proposé chaque année aux éphèbes dans le sanctuaire d'Agraulos. Ils jurent en effet de regarder le blé, l'orge, la vigne, l'olivier comme les frontières (horois - les bornes) de l'Attique et on leur enseigne à considérer comme étant à eux la terre cultivée et fertile." DETIENNE (1970), p.9, écrit qu'il y a une «consubstantialité du groupe politique et de l'olivier ".

19. Plut., Thésée, $23,7$.

20. Voir LEDUC (2016), p. 16, n. 7.

21. Lysias, VII, Sur l'olivier sacré, $12 ; 15 ; 41$; Aristt., Const. Athéniens, 60, 2. 
22. Pollux, IX, 17 ; Hésychius, s.v. astē elaia et s.v. Athenais.

23. FLAMENT (2007), p. 25 et le chapitre sur «Le monnayage glaucophore», p. 25-152 pour l'ensemble du dossier numismatique. L'olivier apparaît également sur un décret d'alliance entre Athènes et Samos (403/2 av. n.è.), IG I $\mathrm{I}^{3} 127$; II ${ }^{2} 1$, Athènes, Musée de l'Acropole, 1333 présentant Athéna et Héra en dexiosis, le bouclier d'Athéna reposant sur un « tronc » d'arbre sans feuilles. Ce tronc évoque évidemment l'olivier d'Athènes, en suivant BLANSHARD (2006), p. 20 (« olive stump $»)$ et en dépit deLAWTON (1995), p. 88-89, $\mathrm{n}^{\circ}$ 12, pl. 7 qui y voit « a prop rather than her olive tree » et HOLTZMANN (2003), p. 192 qui indique que la «nature est suggérée, à l'arrière plan, par un tronc d'arbre». Sur l'analyse iconographique des en-têtes de décret et la question de la « personnification d'Athènes », voir PAMPANAY (2017).

24. S.v. stephanon ekpherein.

25. Euripide, Ion, 1413-1436, parmi les objets placés par Créuse (une étoffe frangée brodée d'un motif de Gorgone qui rappelle l'égide, des serpents d'or), il y a une couronne de l'olivier d'Athéna: "sur toi, enfant, j'avais posé une couronne de feuilles d'olivier, du premier olivier qu'Athéna apporta sur son rocher, jadis » (1429-1430).

26. Sur l'analyse des représentations de la naissance d'Érichthonios, voir DARTHOU - STRAWCZYNSKI (2006), p. 54-59.

27. Palerme, Musée archéologique 2365 (425-375 av. n.è.), BA 217525 ; ARV 1339.3 ; REEDER (1995), p. 262-264, fig. 72.

28. Richmond, Museum of Fine Arts 81.70 ; BA 10158 (425-375 av. n.è.) ; REEDER (1995), p. 260-262, fig. 71. Voir OAKLEY (1987).

29. En couronne sur Héphaïstos et Zeus, en rameau surplombant la poursuite entre Éos et Céphale sur la face B.

30. Peintre d'Érichthonios (450-400 av. n.è.) ; Londres, British Museum E372 ; BA 216598 ; ARV 2 1218.1 ; REEDER (1995), p. 257-258, fig. 69.

31. DARTHou (2000), p. 154-164. Par exemple, Isocrate, Panath., 126 : «À partir de cette époque (Erichthonios), tous ceux qui vinrent après lui, et ils sont nombreux, transmirent à leurs enfants leurs biens et leur pouvoir, jusqu'à Thésée. "

32. DARTHOU (2005), p. 69.

33. L'autochtonie se décline sur blastanō (Eur., Ion, 262), phuō (Aristt., Pol., 269b, 271a-b ; Isocrate, Panég., 24 ; Panath., 124 ; Eur., fr. 360, 8) et rizē (Nonnos, Dion. XLI, 65) ; voir DARTHOU (2000), p. 165166 ; LEDUC (2015). Sur l'autochtonie, voir l'étude centrale de LORAUX (1996), notamment p. 7-25 et 35-73.

34. Eur., Ion, 1576 ; pour ses descendants rattachés à la lignée autochtone.

35. Plut., Propos de table, 8, 2 (723f): «C'est parce qu'aux premières feuilles qui se détachent viennent en succéder d'autres que, comme les cités, chacune demeure toujours vivace et persistante."

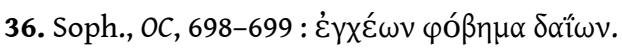

37. Schol. Soph., OC, 698-699, publiée in XENIS (2018).

38. Pour les armes sonores qui assourdissent et évoquent la présence des dieux, voir BROUILLET (2016), p. 60-70; pour la dynamique des épisèmes, LISSARRAGUE (2008).

39. Sans que l'on doive assimiler les épisèmes à des blasons, voir LISSARRAGUE (2009), p. 239. Sur l'ornement des armes et la kosmèsis de l'armure, voir LISSARRAGUE (2017).

40. Sur sēma, voir CHIESA (1991) et DARTHOU (2000), p. 201-204. LISSARRAGUe (2006) ; LISSARRAGUE (2008), p. 4 indique qu'il y a un «effet d'osmose entre la figure du guerrier et l'image sur le bouclier".

41. CHASE (1979) dresse la liste des épisèmes de boucliers, sans réellement les analyser ni mentionner d'olivier ;JACQUEMIN (1973) mentionne, quant à elle (p. 143, $\mathrm{n}^{\circ}$ 48), un seul épisème de bouclier (Fig. 14). LISSARRAGUE (2009), p. 240 recense également les motifs 
d'épisèmes à partir de la baseBEAZLEY (http://www.beazley.ox.ac.uk/index.htm) sans mentionner d'olivier.

42. Sur les possibilités graphiques de l'épisème, voir LISSARRAGUE (2007), p. 151-155.

43. Sur la difficulté de faire la distinction entre olivier et laurier et plus généralement entre les divers végétaux d'après leurs feuilles, voir KUNZE-GÖTTE (2006), p. 7-13. Sur la difficulté d'identifier un arbre comme un olivier, voir CHAZALON (1995), p. 111-113. Sur la question de l'identification des végétaux et le « réalisme » de leur représentation, voir les réflexions de KEI (à paraître).

44. Pour la place des végétaux dans la composition voir KEI (2016) et DIETRICH (2010).

45. L'olivier peut paraître difficile à identifier dans une logique botanique (par ses feuilles ou ses fruits) pour les vases représentant une tête d'Athéna accolée à une branche ; par exemple : New York, Metropolitan Museum 75.2.22; Varsovie, musée archéologique 198501 ; Adolphseck, Schloss Fasanerie 58. Il en va de même des représentations de chouettes entourées de rameaux (sans fruits) sur les 118 occurrences de vases (très normés) consultées dans la base BEAZLEY : par exemple Capua, Museo Campano, 7946; Malibu, The J. Paul Getty Museum, 77.AE.96 ; Capua, Museo Campano, 222 ; Bryn Mawr, Bryn Mawr College, P97 ; Munich, Arndt, New Haven, Yale University, 1913.161. Pourtant, les rameaux sont à interpréter en polarité avec Athéna ou la chouette car ils forment un système de «signes » cohérent; à la suite de MONBRUN (2007), p. 563, cette abondante production de skyphoi représente visiblement « la chouette et l'olivier, les deux emblèmes d'Athéna et d'Athènes ». Voir JOHNSON (1953) et (1955) pour ces skyphoi.

46. LISSARRAGUe (2015), p. 12. LISSARRAGUe (2009), p 240, indique que le dossier des épisèmes a été analysé «plus comme un lexique d'éléments isolés que comme une syntaxe d'images qui font système ».

47. LISSARRAGUe (2004), p. 103, 105.

48. Fig. 4 : Berlin, Antikensammlung 3979 ; BA 45373 (475-425 av. n.è.) ; BENTZ (1998), planche 84 ; Fig. 5 : Athènes, Céramique, PA700, BA 44193 (500-450 av. n.è.) ; BENTZ (1998), planche 85 ; Fig. 6 : Balagrai, Musée 2 ; BA 9026150 ; (400-300 av. n.è.) ; BENTZ, ESCHBACH (2001), pl. 10.1 ; Fig. 7 : SaintPétersbourg, Ermitage 17794; BA 303118; ABV 410.2; Add 107 (500-450 av. n.è.); SMETs (1936), p. 95, identifie cet épisème comme une couronne d'olivier; Fig. 8 : Amphore panathénaïque découverte à Barca en 1990 ; MAFFRE - FADL ALI (1993), p. 94 (dessin de M.-G. FROIDEVAUX, CNRS/ IRAA), qui identifient l'épisème comme une couronne de « laurier » (p. 96), conservée au moment de la publication dans les réserves du musée de Cyrène ; noter aussi Berne 23725 ;BA 303117 ; ABV 410.1 (500-450 av. n.è.) pour lequel SMETs (1936), p. 95, indique comme épisème " une couronne ». Sur les amphores panathénaïques, voir NEILS (1992), p. 29-51.

49. Berlin, Antikensammlung 3979 (Fig. 4), Athènes, Céramique PA700 (Fig.5) (deux cercles incisés); Saint-Pétersbourg, Ermitage 17794 (Fig. 7). Cela peut rappeler visuellement les «dix cercles de bronze » sur les bords du bouclier d'Agamemnon (Hom., Il. XI, 33).

50. Aristt., Const. Athéniens, 40, 3 et IG II ${ }^{2} 2311,52$ (pour l'huile). Pour la couronne d'olivier, « signe du vainqueur ", voir par exemple Pind., Ol. III, 13 ; IV, 10 et XI, 13, et Porph., Antre des nymphes, 33 : «il (l'olivier) est consacré à Athéna et on lui emprunte des couronnes pour les athlètes victorieux. » Voir KYLE (1996). Voir une amphore panathénaïque à l'épisème de Nikè tendant une couronne d'olivier, Copenhague, Ny Calsberg Glyptotek 3606 ; BA 8782 ; BENTZ (1998), pl. 77.

51. HALM-TISSERANT (1986), p. 250, donne la liste d'une quarantaine d'épisèmes en figures noires pour le bouclier d'Athéna sans mentionner l'olivier (elle indique seulement « feuille » et « lierre » comme épisèmes végétaux).

52. On indique également un cratère en calice béotien, Munich, Antikensammlung 6488 ; BA 9037014, qui figure Athéna (Nikè derrière elle) face à Poséidon. Le bouclier d'Athéna porte en épisème une couronne d'olivier.

53. Hanovre, Kerster-Museum 1968.93, Peintre d'Alkimakos (vers 450 av. n.è.) ; BA 1925 ; Add. ${ }^{2}$ 392 ; CVA Hanover I pl. 44 ; LIMC Athena 501. 
54. Contrairement à la légende du LIMC (Athena 501) indiquant que le « bouclier est décoré d'une guirlande de laurier ».

55. Pour l'olivier signe de victoire dans l'eris: Plut., Thém., 19, 4 ; Ael. Aristide, Disc. panath., 42 (nikēs sumbolon); Ovide, Métam. VI, 82.

56. Je remercie N. Kei d'avoir attiré mon attention sur cette inscription.

57. Ferrare, Museo Nazionale di Spina 3031, attribué au Peintre de Bologne 279 (475-425 av. n.è.) ; BA 207095 ;ARV² 612.1, 1662 ;Para 397. La scène est identifiée dans la base BEAZLEY comme figurant Athéna, les Argonautes et des Amazones.

58. Athènes, Musée de l'Acropole 2568 ; BA 9091 ; LIMC Athena 600 ( $1^{\text {re }}$ moitié du ve s. av. n.è.).

59. GRAND-CLÉMENT (2010).

60. Par exemple Athéna représentée de profil face à un rameau d'olivier sur des lécythes à f.r., NY Metropolitan Museum 75.2.22 (475-425 av. n.è.); Varsovie, musée archéologique, 198501 et Adolphseck, Schloss Fasanerie, 58 (475-425 av. n.è.); ou Athéna tenant dans sa main une branche d'olivier (péliké à f.r., Paris, Louvre, G233, 500-450 av. n.è.).

61. Fig. 12, 12bis et 13 : Adolphseck, Schloss Fasanerie 77 ; BA 217589; ARV ${ }^{2} 1346.1$; Para 482; 1346.1 (410-400 av. n.è.) ; REEDER (1995), p. 264-266, fig. 73 ; LOCHIN (2000), fig. 1-2 p. 331 ; SMITH (2011), fig. 9.1.

62. Étudiée par LOCHIN (2000).

63. Les deux cimiers du casque d'Agamemnon renforcent son aspect effrayant (Hom., Il. XI, 41-42 « dont le panache en l'air oscille, effrayant»).

64. Xén., Rép. Lac. XI, 3 ; VERNANT (1985), p. 42-45, analyse cette figure de la Gorgone, repris par PARADISO (1992), p. 59-60.

65. Plut., Lyc., 22, 1-2.

66. Sur ce sujet, voir les analyses de FRONTISI-DUCROUX (2012), p. 113-125.

67. Sur le gorgoneion épisème du bouclier d'Athéna, voir HALM-TISSERANT (1986). Sur les liens entre bouclier et gorgoneion dans le mythe de Persée, voir FRONTISI-DUCROUX (2012), p. 65-75 ; LISSARRAGUE (2008), p. 3.

68. On note que cette composition est comme saturée de l'olivier d'Athéna qui apparaît en arbre, en rejetons sur des souches ou à terre (avec des olives), en couronne, en épisème et en rameaux.

69. Voir la description du bouclier d'Agamemnon chez Homère (Il. XI, 35-37) : « Gorgone aussi s'y étale en couronne (estephanônto), visage d'horreur aux terribles regards, qu'entourent Terreur (Deimos) et Déroute (Phobos)», et Pindare (Pyth. X, 47) pour la description de la «crinière » de serpents terrifiants.

70. C'est une hypothèse formulée par LAFFARGUE (2017), p. 214.

71. Nous disposons seulement d'Hésychius, s.v. stephanon ekpherein.

72. HALM-TISSERANT (1995), les portes étudiées ne semblent pas porter de rameaux d'olivier et l'auteur n'en mentionne pas dans son étude très complète.

73. Eur., Ion, 1413-1436, voir supra n. 25.

74. Cléarque de Soles, cité par Athénée, XIII, 555d ; Souda, s.v. Prometheus. DARTHOU -STRAWCZYNSKI (2006), p. 58 ; GOURMELEN (2004), p. 102-105.

75. Pour l'olivier comme sēmeion dans le cadre de l'eris entre Athéna et Poséidon : Strabon, IX, 1, 16 et DARTHOU (2000), p. 201-205; pour le bouclier comme sēmeion: Hérodote, I, 171 ; Euripide, Phén., 142, 1111 et 1114.

76. Pour l'olivier comme l'astēe elaia, voir Pollux, IX, 17 et Hésychius, s.v. astēe elaia et s.v. Athenais. 77. Peintre de Suessula (425-375 av. n.è.), New York, Metropolitan Museum 17.46.1; BA 217569 ; $A R V^{2}$ 1344.2. Cela a été répertorié comme la seule représentation d'un épisème d'olivier dans le mémoire de maîtrise de JACQUEMIN (1973), p. 143.

78. Pour les étoiles sur les armes, voir la cuirasse de Patrocle (Il. XVI, 133-134) et pour le bouclier d'Achille, Eur., Él., 465-470 (il est un « effroi » pour les regards d'Hector). 
79. Chicago, Art Institute 22.2197 ; BA 207068 ; ARV 610.21 (475-425 av.n.è.) ; YATROMANOLAKIS (2009), p. 404 fig. 8.

80. Ces frises sont assez traditionnelles mais, si l'on admet qu'elles ne sont pas seulement décoratives, cela peut faire écho à la couronne en épisème et l'on peut se poser la question de savoir si ce sont des feuilles d'olivier.

81. Dans la base BEAZLEY, c'est identifié comme du lierre ("ivy leaves»), ce qui ne paraît pas concorder ici avec la forme des feuilles, plus caractéristiques pour le lierre, ni avec la cohérence de l'image, ni sur la frise sous le col, ni en épisème, ni en rameau.

82. Sur la brillance et le chatoiement des armes, kosmos, poikilia et ganos, voir KEI (2011), surtout p. 238-239 ; LISSARRAGUE (2017), p. 132-134 sur la kosmēsis de l'armure.

83. Sur l'éclat du corps des dieux, voir VERNANT (1989), p. 33-39 ; GRAND-CLÉMENT (2017), p. 46-50.

84. GRAND-CLÉMENT (2010), p. 16.

85. DETIENNE (2009) dans le chapitre «L'œil de bronze» (p. 174-177) montre comment Athéna Glaukōpis, l'égide, le gorgoneion, et la chouette concourent à dessiner cette déesse qui éblouit et fascine par un éclat terrifiant. Voir GRAND-CLÉMENT (2011), p. 399-403 pour l'analyse de cette épithète Glaukōpis réservée à Athéna, qui «dénote un éclat splendide en même temps qu'inquiétant et dangereux » (p. 402).

86. Voir MONBRUN (2007). L'olivier est étroitement associé à la chouette sur les monnaies d'Athènes, mais également sur toute une série de vases qui affichent des chouettes encadrées de rameaux d'olivier ; voir JOHNSON (1953) et (1955).

87. Sur Glaukōpis, voir DETIENNE (2009) p. 174-177, et la belle étude de GRAND-CLÉMENT (2010) et son parallèle avec les glaukōpes mentionnés chez Pindare (Ol. VI, 45-46), des reptiles au regard « étrange et pénétrant » qui recouvrent une fonction « défensive, apotropaïque » (p. 17-18).

88. Fig. 11. D'ailleurs, sur un plat attique à f.n. (Baltimore, Walters Art Gallery 48.215, vers 600550 av. n.è.), affichant un gorgoneion central entouré d'une double frise où se croisent figures léonines, sphinx et sirène, une chouette, seule figure représentée de face, darde son regard frontal vers le spectateur et semble « redoubler » le regard pétrifiant de la Gorgone.

89. Théophr., Rech. plantes I, 10, 1, indique que l'olivier fait partie de ces arbres qui « retournent, semble-t-il, la face supérieure de leurs feuilles après le solstice d'été ». Voir aussi Porphyre, L'Antre des nymphes, 32; AMIGUEs (2002), p. 393 pour cette "motilité végétale"; LEDUC (2006 [2009]), p. 149, propose, elle, une analogie qui nous semble abusive entre la dérobade de cette «feuillaison à l'étreinte du brûlant soleil d'été » et la « dérobade d'Athéna » face à « l'étreinte du brûlant forgeron » Héphaïstos.

90. Porphyre, L'Antre des nymphes, 32, parle de "parties blanches» (ta leuka), " parties les plus blanches » (ta leukotera), de «blanche lumière » (to leukon); P. CHANTRAINE, s.v. leukos note cette notion de «blanc lumineux » et d'« éclat ». Voir GRAND-CLÉMENT (2010), p. 361 pour la capacité à « réfléchir la lumière », et l'étude du terme p. 361-367 ; LEDUC (2006 [2009]), p. 151, indique que la face inférieure de la feuille d'olivier qui se retourne est «blanchâtre ", veloutée au toucher et a des reflets brillants, quasi métalliques au soleil », face qui lui permet de se prémunir contre l'évaporation; le qualificatif glaukê évoque alors cet «arbre blanc étincelant d'éclats métalliques ».

91. Eur., Tr., 801-803.

92. Aristoph., Acharn., 1128 et scholie ; FRONTISI - DUCROUX - VERNANT (2005), p. 191-193, ont, en étudiant la « lécanomancie », fait apparaître que le bouclier huilé s'apparente au miroir.

93. FRONTISI-DUCROUX - VERNANT (2005), p. 191-192, citent une scholie à ce vers (Aristoph., Acharn., 1128) qui indique que «c'était une habitude pour ceux qui partent au combat de fourbir leurs armes afin que, par leur aspect brillant, elles effrayent l'ennemi ». Repris par JUBIER - LAURENS (2007), p. 111, qui analyse le bouclier comme une arme offensive dont « l'éblouissement provoqué 
par le bronze étincelant paralyse » en citant VERNANT (1985b), p. 40, pour son étude du «bronze éblouissant » qui provoque la «terreur dans l'âme de l'ennemi ».

94. Peintre de Nausicaa (450 av. n.è.), Richmond, Virginia Museum 62.1.1; BA 275462; ARV 1683.48BIS ; Para 452 ; REEDER (1995), p. 411-413, fig. 135.

95. Contrairement à REEDER (1995), p. 412, qui voit dans l'olivier une «protection» (« her elbow pressed against the base of the tree as if for protection »).

96. On rappelle DIETRICH (2010).

97. Comme c'est le cas sur une pyxide à fond blanc où Méduse est étendue sur des " rochers » tandis qu'un arbre feuillu est figuré à l'arrière-plan, Louvre MNB1286; BA 209561; ARV 1669 (475-425 av. n.è.).

98. DIETRICH (2010), p. 486, vase publié p. 488, fig. 416, sans pour autant analyser la symbolique de cet olivier. Pour l'auteur (p. 480), les rochers ou éléments du « socle terrestre » sont de plus en plus remplacés par des « lignes de sol » à partir de la seconde moitié du ve siècle et l'on peut donc supposer que le corps de Méduse, qui présente une certaine ondulation, repose sur un élément rocheux ou épouse un contour terrestre. Pour l'auteur, cette absence de « roche " permet de détacher le corps de la Gorgone totalement entourée de vernis noir afin de créer un effet de focalisation.

99. DIETRICH (2010), p. 552.

100. À ce sujet, voir BOTHMER (1957); DEVAMBEZ (1981); STURM (2017); REEDER (1995), p. 373-380 ; LISSARRAGUE - SCHMITT - PANTEL (2009).

101. Platon, Mén., 239a. STEWART (1995) ; MAYOR (2017), p. 318-335 dans son chapitre « La bataille d'Athènes ". Pour les représentations des Amazonomachies à Athènes, voir par exemple Pausanias, I, 17, 2 (sanctuaire de Thésée, bouclier d'Athéna).

102. MAYOR (2017), p. 327-331, pour les représentations et leurs lectures contrastées face aux guerres médiques.

103. Et non pas Héraclès, CALAME (2018), p. 410-412.

104. Plut., Thésée, 27, 1-2, indique bien que les Amazones ont « pénétré dans la cité ", qu'elles ont " campé presque au milieu de la cité »

105. Par exemple, péliké attique à f.r., à la manière du Peintre du Louvre G 433 (425-375 av. n.è.), Varsovie, Musée national 198559, BA 217562. Un Grec au bouclier orné d'un motif "étoilé » affronte une Amazone montée : au centre de ce duel, un olivier affiche l'enjeu du combat.

106. Cratère à volutes attique à f.r., Peintre des satyres laineux (475-425 av. n.è.), New York, Metropolitan Museum 07.286.84 ; BA 207099 ; ARV² 613.1, 1662 ; Para 397 ; LIMC Theseus 267. On signale également un hoplite face à une Amazone, hoplite dont le bouclier est orné, sur la face interne, d'une couronne de feuillage que l'on peut associer à de l'olivier tandis que des rameaux portant des fruits émergent du sol en encadrant les protagonistes (fragments d'une loutrophorehydrie attique à f.r., Athènes, Collection de la troisième éphorie des antiquités préhistoriques et classiques A15396).

107. Couronne qui encercle un arrière-train d'animal, vraisemblablement un équidé.

108. Genève, Musée d'Art et d'Histoire MF238, Peintre de Genève (475-425 av. n.è.) ; BA 207115 ; $A R V^{2} 615.1$; Para 397.

109. Dinos attique à f.r., Groupe de Polygnotos (475-425 av. n.è.), Londres, British Museum, 1899.7-21.5, BA 213658, ARV² 1052.29; LIMC Megareus 1, p. 269, écrit que « l'intérieur du bouclier [est] décoré d'une frise de laurier ».

110. Voir LISSARRAGUE (2008), fig. 6, à propos d'un épisème " à destination non plus de l'ennemi face au bouclier, mais du spectateur face à l'image, du buveur face au cratère »et LISSARRAGUE (2015), p. 23 pour cette captation du regard du spectateur. 
111. Cratère à volutes attique à f.r., Peintre des Niobides (475-425 av. n.è.), Naples, Museo Archeologico Nazionale H2421 (anciennement M1483) ; BA 206941; ARV² 600.13; Para 395 ; REEDER (1995), p. 376-379, fig. 121.

112. Bien notés sur le dessin de FURTWANGLER, REICHHOLD (1904-1932), I, 126, 137, pl. 26-2.

113. Enochoé attique à f.r., à la manière du Peintre du taureau (450-400 av. n.è.), Paris, Musée du Louvre G571 ; LIMC Amazones 328.

114. LEDUC (1990), p. 273-274, écrit « sinon un arbre lithique, du moins un anti-végétal»; elle indique que l'olivier « pétrifiant » est associé à « la destruction et à la mort » par la « fossilisation de l'adversaire » en s'appuyant sur une mention de Théophraste (Rech. plantes IV, 16, 5) indiquant que l'huile est «hostile (polemion) à tous les arbres » ou le passage sur le retournement de ses feuilles qui suspendrait le "cycle végétatif » et qui incarnerait une "dérobade à la cuisson solaire » (Théophr., Rech. plantes IX, 7). Voir la critique de Touzé (2012), p. 110-111.

\section{RÉSUMÉS}

Dans le mythe de fondation d'Athènes, lors de sa querelle avec le dieu Poséidon pour remporter le titre de Poliade, Athéna fait croître un olivier sur le sol rocailleux de l'Acropole tandis que Poséidon fait surgir une mer. Cet olivier qui assure la victoire ne saurait se réduire à une preuve de la puissance protectrice de la déesse. Signe d'Athéna, signe de la cité, signe d'un Athénien, il est étroitement associé à l'identité citoyenne comme à l'identité politique. Mais l'olivier apparaît également comme un motif d'épisème de bouclier sur les vases attiques. Qualifié par Sophocle d'« effroi des armes ennemies », brillant et miroitant comme le bouclier de bronze, il redouble l'éclat du guerrier et propose un motif à penser en polarité avec legorgoneion qui concourt à effrayer l'adversaire. Cette relecture iconographique de l'olivier fait ainsi apparaître que l'arbre d'Athéna oscille entre référence identitaire et rempart fascinant face aux ennemis.

In Athens' foundation myth, Athena, during her contest with the god Poseidon to win the title of Polias, planted an olive tree on the rocky soil of the Acropolis while Poseidon raised a sea. This olive tree that ensures victory cannot be seen just as a proof of the protective power of the goddess. Sign of Athena, sign of the city, sign of the Athenians, it is closely associated with civic and political identity. Yet the olive tree also appears as a shield device on Attic vases. Described by Sophocles as the "dread fear of enemies' weapons", shining and shimmering like the bronze shield, it doubles the warrior's sheen and conveys a pattern to be read in polarity with the gorgoneion that adds to the rival's fright. This iconographic reinterpretation of the olive tree thus reveals that Athena's tree oscilates between a question of identity and a fascinating rampart against enemies.

\section{AUTEUR}

\section{SONIA DARTHOU}

Université d'Évry val d'Essonne - UMR 8210 AnHiMA

sonia.darthou@univ-evry.fr 